\title{
Analgesic and Anti-Inflammatory Effects of Monoacylglycerol Lipase Inhibition in Mice Subjected to Collagen-Induced Arthritis
}

Sara R. Nass

Follow this and additional works at: https://researchrepository.wvu.edu/etd

\section{Recommended Citation}

Nass, Sara R., "Analgesic and Anti-Inflammatory Effects of Monoacylglycerol Lipase Inhibition in Mice Subjected to Collagen-Induced Arthritis" (2015). Graduate Theses, Dissertations, and Problem Reports. 6297.

https://researchrepository.wvu.edu/etd/6297

This Thesis is protected by copyright and/or related rights. It has been brought to you by the The Research Repository @ WVU with permission from the rights-holder(s). You are free to use this Thesis in any way that is permitted by the copyright and related rights legislation that applies to your use. For other uses you must obtain permission from the rights-holder(s) directly, unless additional rights are indicated by a Creative Commons license in the record and/ or on the work itself. This Thesis has been accepted for inclusion in WVU Graduate Theses, Dissertations, and Problem Reports collection by an authorized administrator of The Research Repository @ WVU. For more information, please contact researchrepository@mail.wvu.edu. 


\title{
Analgesic and Anti-Inflammatory Effects of Monoacylglycerol Lipase Inhibition in Mice Subjected to Collagen-Induced Arthritis
}

\author{
Sara R. Nass \\ Thesis submitted to the Eberly College of Arts and Sciences at \\ West Virginia University \\ in partial fulfillment of the requirements for the degree of \\ Master of Science in Psychology/Behavioral Neuroscience
}

\author{
Steven G. Kinsey, Ph.D., Chair \\ Christina L. Duncan, Ph.D. \\ Miranda N. Reed, Ph.D. \\ Department of Psychology
}

Morgantown, WV

2015

Keywords: Rheumatoid arthritis, chronic inflammatory pain, endocannabinoid, mice, MAGL Copyright 2015 Sara R. Nass 


\title{
ABSTRACT \\ Analgesic and Anti-Inflammatory Effects of Monoacylglycerol Lipase Inhibition in Mice Subjected to Collagen-Induced Arthritis
}

\begin{abstract}
Sara R. Nass
Rheumatoid arthritis (RA) is the most prevalent chronic inflammatory joint disease, affecting approximately $1 \%$ of the world population. This autoimmune disease is characterized by pain, stiffness, swelling, and breakdown of cartilage in synovial joints. Current RA analgesic treatments (i.e., pain reducing drugs) are ineffective or induce negative side effects, and so there are many concerted efforts to discover new RA treatments. Cannabinoids have analgesic and anti-inflammatory properties; however, the challenge remains to harness the medical potential of cannabinoids without inducing negative psychoactive effects (e.g., cognitive deficits, emotional disruption, and abuse potential). An alternative approach focuses on the endogenously produced cannabinoids (endocannabinoids). The endocannabinoids 2-arachidonoyl glycerol (2-AG) and anandamide are catabolized by the enzymes monoacylglycerol lipase (MAGL) and fatty acid amide hydrolase (FAAH), respectively. Pharmacological inhibition of MAGL or FAAH increases brain levels of the respective endocannabinoids, 2-AG or anandamide, and significantly decreases inflammatory pain. The present study tested the hypothesis that MAGL inhibition decreases hyperalgesia, locomotor suppression, and allodynia caused by collagen-induced arthritis (CIA), a well-established animal model of inflammatory arthritis. Separate groups of mice subjected to CIA were administered acute or chronic doses of the selective MAGL inhibitor JZL184 and tested for (1) thermal hyperalgesia in the hotplate and tail immersion tests, (2) mechanical allodynia, and (3) suppressed locomotor activity. Thermal hyperalgesia was significantly attenuated by acute JZL184 (8 or $40 \mathrm{mg} / \mathrm{kg}$ ) in the hot plate test, but not the tail immersion test. The lack of JZL184 attenuation of hyperalgesia in the tail immersion test may indicate a JZL184 supraspinal mechanism of action. Although the present study was hampered by ongoing model development, these results suggest that MAGL inhibition may be a promising strategy for the treatment of pain caused by inflammatory arthritis.
\end{abstract}




\section{Table of Contents}

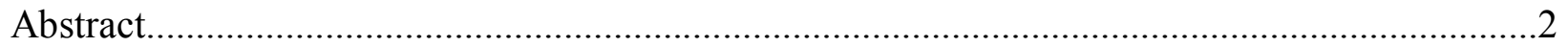

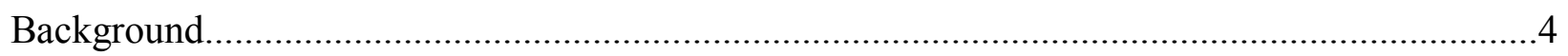

Rheumatoid Arthritis...................................................................................................

Current Rheumatoid Arthritis Treatments...................................................................6

The Endocannabinoid System...............................................................................

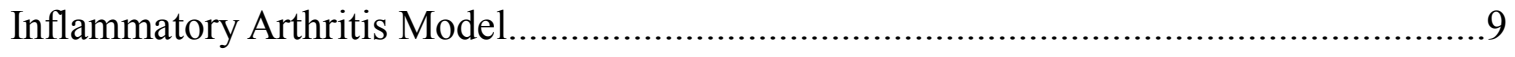

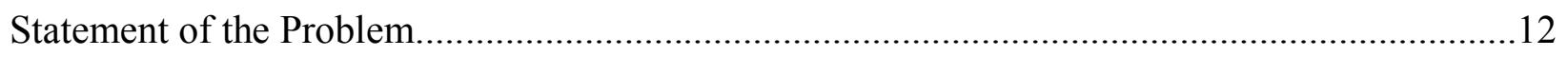

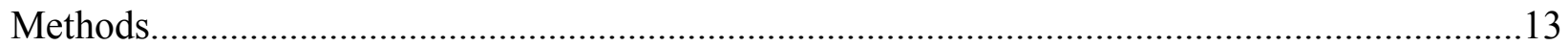

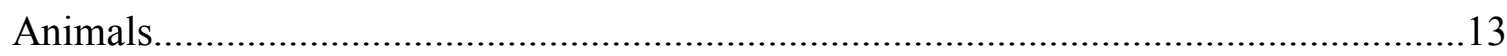

Collagen Induced Arthritis (CIA) immunization..........................................................14

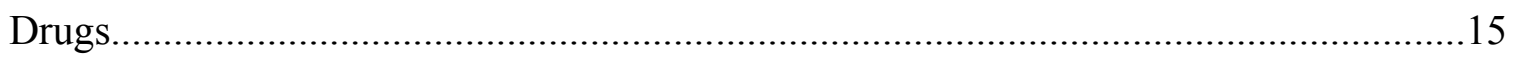

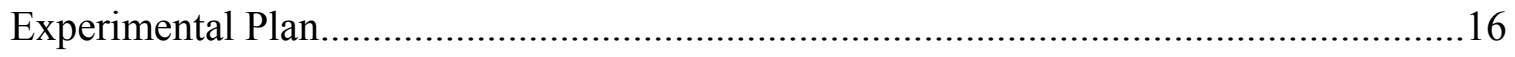

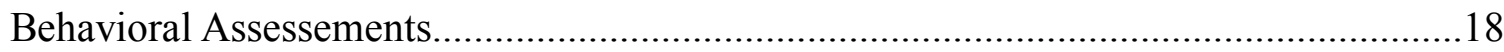

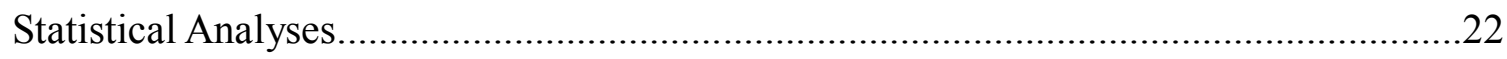

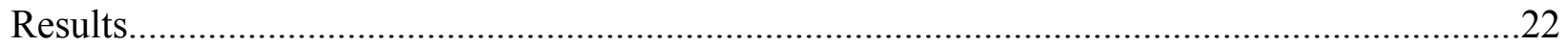

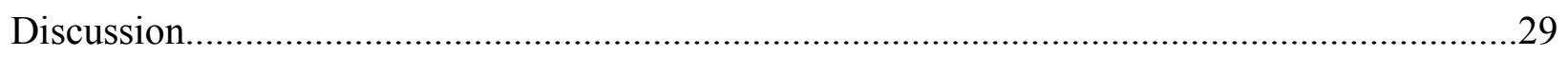

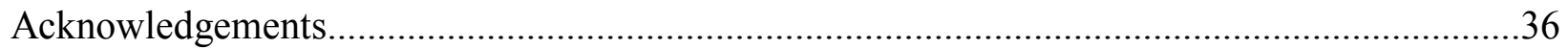

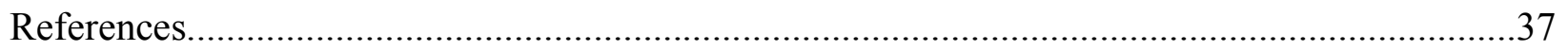

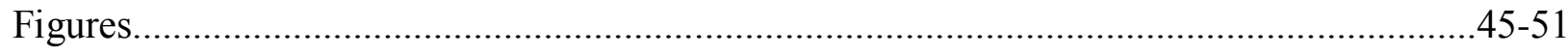

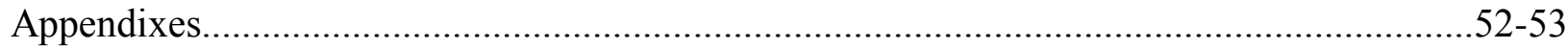




\section{Background}

\section{Rheumatoid Arthritis}

The term "arthritis" encompasses over 100 different medical conditions (CDC, 2012) and can be broadly divided into two different categories: musculoskeletal and inflammatory arthritis. Rheumatoid arthritis (RA) is the most common type of inflammatory arthritis, affecting about $1 \%$ of the population worldwide (Firestein, 2003). RA is a systemic inflammatory disease categorized by swelling and erosion of multiple synovial joints (i.e., knees, elbows, wrists, hips, and fingers) (CDC, 2012). Other symptoms of RA, caused by systemic inflammation, include anemia, fatigue, generalized bone loss, artherosclerosis, and lung tissue damage (Moreland, \& Curtis, 2008). Although the etiology of RA is not well understood, it is considered an autoimmune disease, in that the host's immune system attacks healthy tissues, causing localized inflammation and tissue damage (Boissier et al., 2012). During the autoimmune process, there is a release of proinflammatory mediators (i.e., cytokines and chemokines) that increase nociception (i.e., pain) by either directly activating nociceptors or producing a sensitization of the somatosensory nervous system that leads to an increase in inflammation and pain (Scholz \& Woolf, 2002).

In addition to being the primary negative symptom among RA patients, increased nociception contributes directly to chronic disability by limiting mobility. Perhaps surprisingly, RA patients report chronic pain, rather than joint damage, as the primary reason for their limited mobility and decreased quality of life (Lee, 2013). Chronic pain also causes psychological and physiological distress, which can negatively affect disease outcome. For example, during the

early stages of the disease, patients who rate overall pain as "high" report increased levels of disability one year later, as compared with patients who rate their pain as relatively lower (Walsh 
\& McWilliams, 2012). Chronic pain can also cause patients to forgo physical activities that may otherwise be beneficial to their physical and emotional health. The pain, as well as fatigue induced by sleep disturbance, can then lead to decreased productivity (Walsh \& McWilliams, 2012). Mood disturbance can also affect chronic pain patients. Pain causes depression, and then the altered affect makes it increasingly difficult to cope with the pain, thus causing a vicious cycle. In other words, in addition to the pain itself, decreased physical activity and increased mood and sleep disturbance also lead to an immeasurable decrease in the quality of life of patients suffering from RA. What is perhaps easier to quantify is the cost of RA to the US healthcare system, which is staggering with $\$ 545$ million spent in 2009 alone, on hospital visits directly related to this disease (CDC, 2012).

The main cause of widespread pain in RA patients is chronic inflammation of the synovium, which is the smooth lining of the joint. In the acute inflammatory phase, inflammatory mediators elicit local inflammation by activating neutrophils, which are a type of short-lived white blood cells that play a major role in the innate immune response. When inflammation becomes chronic, as with RA, the neutrophils are replaced by macrophages and Tcells at the site of inflammation (Medzhitov, 2008). Macrophages (literally "big eater" cells) are relatively long-lived white blood cells that ingest foreign bodies and produce proinflammatory cytokines (e.g., tumor necrosis factor (TNF), interleukin-1 (IL-1), gamma interferon (IFN $\gamma$ ) and interkeukin-6 (IL-6)) and chemokines. Proinflammatory cytokines function to modulate the inflammatory response, and chemokines recruit other inflammatory cells to the site. In addition to increasing localized inflammation to attack the joint tissue, these signaling molecules help to orchestrate differentiation and maturation of B-cells, which produce antibodies against the target tissue, thus further exacerbating the inflammatory immune response (Scrivo, Franco, Spadaro, \& 
Valesini, 2007). The abundance of T-cells, macrophages, and pro-inflammatory cytokines (TNF,

IL-1, and IL-6) found in the synovial fluid of RA patients supports this cell-mediated autoimmune process as a mechanism for chronic inflammation in RA (Boissier et al., 2012).

\section{Current Rheumatoid Arthritis Treatments}

To date, the main foci of treating RA have been to (1) reduce the proinflammatory immune response, and (2) reduce RA associated pain. Disease-modifying antirheumatic drugs (DMARDs) and glucocorticoids (steroids) are popular treatments. Despite the effectiveness of these medications in suppressing the disease progression, they also evoke harmful side effects and are often ineffective in reducing pain. For example, when introduced later in the disease progression, DMARDs are generally ineffective as analgesics. Even when introduced early, many patients report the presence of moderate pain regardless of DMARD treatment (Lee, 2013). Similarly, steroids such as glucocorticoids are effective analgesics when administered in the short-term, but this analgesia quickly abates as the patient builds tolerance to the steroids (Lee, 2013). Perhaps more alarming is that chronic glucocorticoid treatment can induce insensitivity to one's own steroid hormones (Dinsen, 2013), which can lead to many side effects, including dysregulated immune function on a broad scale. In severe cases where DMARDs or glucocorticoids are ineffective in slowing the progression of the disease, biologic therapies that suppress specific cytokine responses (i.e., TNF, IL-1, \& IL-6) are often used (Al-Shakarchi, Gullick, \& Scott, 2013). However, as with steroid treatments, cytokines mediate many different cell types and functions, and so these drugs are somewhat non-selective and can cause negative side effects along with decreased analgesic efficacy over time (Barton, 2008). Furthermore, any immunosuppressive treatment has the potential to leave the patient with an increased vulnerability to infection. 
Due to the side effects detailed above, nonsteroidal anti-inflammatory drugs (NSAIDS) have become increasingly popular for attenuating inflammatory pain, with comparatively fewer side effects than the alternatives listed above (Lee, 2013). Nevertheless, NSAIDs are not without risk. Chronic NSAID use can cause gastrointestinal bleeding, renal impairment, and increased risk of cardiovascular events, all of which are potentially life threatening (Walsh \& McWilliams, 2012). The increased cardiovascular risk of NSAIDs may be especially problematic for patients with RA, who already have an increased cardiovascular risk, as compared with the general population (Walsh \& McWilliams, 2012).

\section{The Endocannabinoid System}

Due to the adverse impact that chronic pain has on patients' lives, many choose selfmedication with drugs of abuse, most commonly with Cannabis sativa. Cannabis has been used to treat a variety of ailments, including pain, for thousands of years (Mechoulam \& Parker, 2013). Cannabis and similar compounds (cannabinoids) have anti-inflammatory properties and also elicit antinociceptive effects by inhibiting neuronal transmission in pain pathways. Cannabinoid induced analgesia (i.e., pain reduction) has been reported in a variety of clinical and preclinical pain models (Guidon \& Hohmann, 2009). In addition to chronic pain, Cannabis also has analgesic and immunomodulatory effects in a variety of diseases such as multiple sclerosis, AIDS, and amyotrophic lateral sclerosis (Kogan \& Mechoulam, 2007). In the 1960s, the main psychoactive component of Cannabis, $\Delta^{9}$-tetrahydrocannabinol (THC), was isolated and synthesized (Gaoni \& Mechoulam, 1964). However, the undesirable psychomimetic side effects, including deficits in attention and cognitive function, coupled with the abuse potential of THC and other exogenous cannabinoids decrease enthusiasm to use these drugs as therapeutic analgesics (Crowe, Nass, Gabella, \& Kinsey, 2014). Instead, a rapidly growing body of research 
indicates that the endogenous cannabinoid (i.e., "endocannabinoid") system may offer promising new targets for pain treatment.

There are two endocannabinoid (eCB) receptors that have been identified and cloned: cannabinoid receptor $1\left(\mathrm{CB}_{1}\right)$ and cannabinoid receptor $2\left(\mathrm{CB}_{2}\right)$. The $\mathrm{CB}_{1}$ receptor is expressed throughout the body and mediates most of the psychoactive effects of cannabinoid agonists, including hypothermia, catalepsy, and cognitive deficits (Crowe et al., 2014; Nass et al., 2015; Herkenham, Lynn, Johnson, Melvin, de Costa, \& Rice, 1991). The $\mathrm{CB}_{1}$ receptor is also expressed in central nervous system (CNS) areas associated with pain (i.e. the amygdala, periaqueductal gray, and dorsal horn of the spinal cord), indicating that the eCB system is located in appropriate areas to modulate pain (Schlosburg, et al., 2009). On the other hand $\mathrm{CB}_{2}$ is expressed mainly in immune tissues, but can also be found in the CNS on microglia (the macrophages of the CNS) and in low levels in the brainstem (Mechoulam \& Parker, 2013). Within the immune system, $\mathrm{CB}_{2}$ is expressed on a variety of cells (i.e. B cells, natural killer cells, monocytes, neutrophils, and other lymphocytes) with different levels of expression depending on the activation state of the cell and the type stimulation (Rom \& Persidsky, 2013). There are two major endocannabinoids: $\mathrm{N}$-arachidonoylethanolamine (AEA; anadamide) and 2-arachidonoylglycerol (2-AG), that activate and bind to both $\mathrm{CB}_{1}$ and $\mathrm{CB}_{2}$ (Mechoulam \& Parker, 2013).

Unlike other neurotransmitters, which are stored in vesicles, endocannabinoids are synthesized de novo and then rapidly metabolized by enzymes, thus resulting in a short span of activity. Anandamide is primarily regulated by fatty acid amide hydrolase (FAAH) and 2-AG is predominately regulated by monoacylglycerol lipase (MAGL; Figure 1) (Mechoulam \& Parker, 2013). Due to its rapid metabolism MAGL, it is impractical to exogenously administer 2-AG as 
therapeutic treatment. However, pharmacological inhibition or genetic deletion of MAGL increases the endogenous levels of 2-AG and results in analgesia (Long et al., 2009).

FAAH and MAGL inhibition attenuates analgesia in animal models of acute inflammatory pain. Administration of the FAAH inhibitor URB597 attenuates hyperalgesia in the complete Freund's adjuvant (CFA) model of acute inflammatory pain (Schlosburg et al., 2009). CFA is an emulsion of paraffin oil containing a surfactant and heat killed Mycobacterium tuberculosis that induces an inflammatory response, without the development of tuberculosis (Billiau \& Matthys, 2001). URB597 also attenuates hyperalgesia and edema caused by intraplantar injection (into the ventral footpad) of the bacterial endotoxin lipopolysacharride (Naidu, Kinsey, Guo, Cravatt, Lichtman, 2010). Similarly, intraplantar injection of the seaweed extract carrageenan elicits localized edema and thermal and tactile hyperalgesia in mouse paws that is attenuated by URB597 administration (Schlosburg et al., 2009). The carrageenan inflammatory model has also been used very recently to evaluate the analgesic and antiinflammatory effects of MAGL inhibition. Carrageenan is a seaweed extract and common food additive that, when injected, causes localized pain and inflammation. The MAGL inhibitor JZL184 attenuates carrageenan-induced acute paw edema inflammatory pain (Ghosh et al., 2013). Thus, there is evidence to support the idea that MAGL inhibition may also reduce inflammatory pain in a chronic model such as inflammatory arthritis.

\section{Inflammatory Arthritis Model}

Animal models of rheumatoid arthritis are used to increase the understanding of the pathogenesis of the disease and evaluate potential therapeutic treatments. The best characterized mouse model of rheumatoid arthritis is collagen-induced arthritis (CIA). In the CIA paradigm, 
mice are injected with an emulsion of type II bovine collagen mixed with an equal part of complete Freund's adjuvant (Brand, Latham, \& Rosloniec, 2007; Kinsey, Naidu, Cravatt, Dudley, \& Lichtman, 2011a). Four to eight weeks after the initial immunization, mice show clinical signs of arthritis (e.g., paw swelling, redness) as well as cartilage destruction, ossification, pronounced synovitis, and periarticular inflammation (Brand et al., 2007; Inglis, Simelyte, McCann, Criado, \& Williams, 2008). During the progression of arthritis, T-cell, proinflammatory cytokines, and anti-collagen antibody responses increase (Brand et al., 2007; Inglis et al., 2008). Although the progression of CIA is more rapid than in the human disease (Bendele, 2001), both mice and RA patients have the extensive pannus (i.e., irregular tissue formation) associated with cartilage destruction and increased t-cell and pro-inflammatory cytokine response in their synovial joints. Due to the aforementioned similarities between RA and CIA the model has several advantages over other animal models of inflammatory arthritis. For example, the collagen-antibody-induced arthritis (CAIA) model is induced by transferring anti-collagen antibody and administering the gram-negative bacteria marker lipopolysaccharide (LPS) to mice (Khachigian, 2006). Unlike RA and CIA the CAIA model progresses on a rapid time course and does not involve T-cells in the pathogenesis (Khachigian, 2006; Asquith, Miller, McInnes, \& Liew, 2009). T-cells are one of the main immune cells that are activated in RA (Boissier et al., 2012). The TNF- $\alpha$ transgenic mouse model of arthritis is induced by an overexpression of human TNF- $\alpha$. It has a similar pathogenesis to RA and CIA, but unlike RA and CIA the TNF- $\alpha$ model does not produce rheumatoid factor or involve T-cells (Bevaart, 2010). Rheumatoid factor is an antibody that develops against self-tissue and can be found in the serum and joint fluid of RA patients (Boissier et al., 2012). 
Despite the well-known anti-inflammatory and analgesic properties of cannabinoids, a paucity of research focuses on the effects of cannabinoids in CIA. Administration of exogenous cannabinoids attenuates clinical signs of arthritis and joint damage, while having an immunosuppressant effect in CIA (Malfait et al., 2000; Sumariwalla et al., 2004). The antiinflammatory and analgesic effects of anandamide have also been evaluated through FAAH inhibition in CIA. Administration of the FAAH inhibitor URB597 or genetic deletion of FAAH attenuates thermal hyperalgesia (sensitivity to noxious heat) in the hot plate and tail immersion tests in mice subjected to CIA. Furthermore, chronic FAAH inhibition reduces CIA-induced paw swelling and joint destruction (Kinsey et al., 2011a). Taken together, these studies indicate that cannabinoids and endocannabinoids attenuate CIA-induced pain and inflammation. However, the possible role of $2-\mathrm{AG}$ is unknown.

2-AG is much more prevalent than anandamide in the CNS, and MAGL inhibition is relatively more potent than FAAH inhibition in models of neuropathic pain and gastric inflammation (Kinsey et al., 2009; Kinsey et al., 2011b). However, there are no reported data on the effects of MAGL inhibition on inflammatory arthritis. This is likely due to a historic lack of selective MAGL inhibitors or MAGL knockout (i.e., genetic deletion) mice. However, with the recent synthesis of highly selective MAGL inhibitors, it is now possible to investigate the efficacy of MAGL inhibition on inflammatory arthritis.

In the present studies, we investigated the analgesic and anti-locomotor suppressed behavioral effects of MAGL inhibition in the collagen-induced arthritis mouse model of inflammatory arthritis. First, we tested the hypothesis that acute treatment with the MAGL inhibitor JZL184 would reduce CIA-induced pain and locomotor suppression. To this end, we tested a range of doses of JZL184. In addition we tested the FAAH inhibitor PF-3845 and the 
glucocorticoid dexamethasone as positive controls. FAAH inhibition attenuates CIA-induced thermal hyperalgesia (Kinsey et al., 2011a) and dexamethasone attenuates LPS-induced thermal hyperalgesia (Naidu et al., 2010). Second, we tested the hypothesis that the observed analgesic effects of JZL184 are mediated by the $\mathrm{CB}_{1}$ receptor. We pretreated mice that had been administered JZL184 with selective $\mathrm{CB}_{1}$ and $\mathrm{CB}_{2}$ receptor antagonists and then tested the mice for hyperalgesia, allodynia, and locomotor suppression. Third, we tested the hypothesis that chronic treatment with JZL184 or PF-3845 would reduce CIA-induced inflammation, hyperalgesia, and allodynia. We quantified the anti-inflammatory effects of MAGL and FAAH inhibition by measuring paw swelling and performing clinical scoring of arthritic changes, and then conducted behavioral assays.

\section{Statement of the Problem}

Rheumatoid arthritis is a chronic autoimmune disease that decreases quality of life and is correlated with increased depression and sleep disturbances (Lee, 2013). Pain is the most salient symptom among patients with RA and also predicts longitudinal changes in disability over the disease progression (Walsh \& McWilliams, 2012). Conventional treatments for inflammatory arthritis include immunosuppressant agents such as steroids and non-steroidal anti-inflammatory drugs (NSAIDs). However, these drugs have numerous negative side effects, including increasing patients' susceptibility to infection.

Current research focuses on the endocannabinoid system as a potential therapeutic target for inflammatory pain, because of the analgesic effects that are unaccompanied by psychomimetic effects (Schlosburg et al., 2009). Selective inhibitors of the two main metabolic enzymes of the endocannabinoid system (FAAH and MAGL) have been shown to reduce pain and inflammation in several animal models of inflammatory pain (Ghosh et al., 2013; Kinsey et 
al., 2011a; Schlosburg et al., 2009). Our lab recently demonstrated that FAAH inhibition reduces the pain and inflammation caused by collagen-induced arthritis (Kinsey et al., 2011a). However, although 2-AG is expressed in the brain at approximately 200 fold higher levels than anandamide, there are no data on the possible analgesic and anti-inflammatory effects of MAGL inhibition, with regard to inflammatory arthritis. Therefore, we evaluated the possible analgesic and anti-inflammatory effects of MAGL inhibition in the collagen-induced arthritis mouse model of inflammatory arthritis.

\section{Methods}

\section{Animals}

Subjects were adult male DBA/1J mice (Jackson Laboratory, Bar Harbor, ME) that were 9-10 weeks old at the start of the experiments. Mice were housed 3-5 per cage in a temperature $\left(20-22^{\circ} \mathrm{C}\right)$ and humidity controlled environment with ad libitum access to food and water. Male DBA/1J mice were used because they are highly susceptible to developing CIA, as compared to females and other mouse strains (Bendele, 2001). In the acute studies, 18-90\% of the mice developed arthritis and were used for testing. However, for the chronic dosing study, all mice were included and $98 \%$ developed arthritis. Mice were randomly assigned to treatment groups. All experimental protocols (14-1007) were approved by the Animal Care and Use Committee at West Virginia University. 


\section{Collagen Induced Arthritis (CIA) immunization}

In the CIA model, CFA is combined with collagen to induce a strong immune response in the presence of collagen. Then the "booster" re-exposure of collagen in IFA induces autoimmunity to self-collagen. Mice were anesthetized with isoflurane, and approximately 100 $\mu \mathrm{l}$ of an emulsion consisting of bovine type II collagen $(2 \mathrm{mg} / \mathrm{ml})$, dissolved in $0.05 \mathrm{M}$ acetic acid (Chondrex, Redmond, WA), in an equal volume of complete Freund's adjuvant (CFA) (see Table 1) was injected intradermally approximately $1.5 \mathrm{~cm}$ from the base of the tail. Twenty-one days later, mice were given a secondary "booster" exposure to the collagen emulsion, but in an equal volume of incomplete Freund's adjuvant (IFA), injected approximately $2 \mathrm{~cm}$ distal to the original injection. Freund's adjuvants have been used since the 1940's to facilitate the induction of animal models of autoimmune diseases. IFA consists of an emulsion of paraffin oil containing a surfactant. To become CFA, heat killed Mycobacterium tuberculosis is added to the emulsion to induce a strong immune response, without the development of tuberculosis (Billiau \& Matthys, 2001). After the "booster" injection, paws were examined every few days for arthritic signs using a clinical scoring system as follows: 0 , normal; 1 , erythema and mild swelling confined to the ankle joint or toes; 2 , erythema and mild swelling extending from the ankle to the midfoot or ankle joint; 3, erythema and moderate swelling extending from the ankle to the metacarpal/metatarsal joints; 4, erythema and severe swelling encompassing the ankle, foot, and digits (Kinsey et al., 2011a). The scores for the hind limbs were summed for each mouse, resulting in a composite arthritis score with a maximum of 8 total points. Foot thickness was also measured with a digital micrometer (Wixey WR100, Thermo Fisher Scientific, Inc.). The experimenter was blinded to treatments when scoring and measuring paws. Due to low incidence of arthritis in most experiments and ongoing model development, mice with a clinical score of 1 
or higher were used in the acute dosing experiments. Mice subjected to CIA that did not develop paw inflammation (i.e. clinical score of 0 ) were classified as non-responders and were not tested in acute dosing experiments. In the chronic dosing experiment all mice were used because it was impossible to determine if the lack of arthritic symptoms was due to non-responsiveness to CIA or drug effects.

\begin{tabular}{|l|c|l|l|l|l|l|l|}
\hline Exp. & Fig. & \multicolumn{1}{|c|}{ Treatment } & Cohort & \multicolumn{1}{|c|}{ Collagen } & \multicolumn{1}{|c|}{ M. Tb } & CFA & Stopcock \\
\hline $1 \mathrm{a}$ & 3 & Acute JZL184 $(8 \& 40 \mathrm{mg} / \mathrm{kg})$ & 2 & $2 \mathrm{mg} / \mathrm{ml}$ & $2 \mathrm{mg} / \mathrm{ml}$ & Light & No \\
\hline $1 \mathrm{a}$ & 4 & Acute JZL184 $(1 \& 4 \mathrm{mg} / \mathrm{kg})$ & $3 \& 4$ & $2 \mathrm{mg} / \mathrm{ml}$ & $4 \mathrm{mg} / \mathrm{ml}$ & Light & No \\
\hline $1 \mathrm{~b}$ & 5 & Acute PF-3845 $(10 \mathrm{mg} / \mathrm{kg})$ & 7 & $2 \mathrm{mg} / \mathrm{ml}$ & $2 \mathrm{mg} / \mathrm{ml}$ & Heavy & Yes \\
\hline $1 \mathrm{c}$ & 6 & $\begin{array}{l}\text { Acute Dexamethasone }(2 \\
\text { mg/kg) }\end{array}$ & 6 & $2 \mathrm{mg} / \mathrm{ml}$ & $4 \mathrm{mg} / \mathrm{ml}$ & Heavy & Yes \\
\hline 2 & 7 & $\begin{array}{l}\text { Acute SR1 or SR } 2(3 \mathrm{mg} / \mathrm{kg}) \\
\& \text { Acute JZL184 }(40 \mathrm{mg} / \mathrm{kg})\end{array}$ & $7 \& 8$ & $2 \mathrm{mg} / \mathrm{ml}$ & $2 \mathrm{mg} / \mathrm{ml}$ & $\begin{array}{l}\text { Heavy } \\
\text { Light }\end{array}$ & Yes \\
\hline 3 & 8 & $\begin{array}{l}\text { Chronic JZL184 } \\
(8 \mathrm{mg} / \mathrm{kg}) \text { or PF-3845 } \\
(10 \mathrm{mg} / \mathrm{kg})\end{array}$ & 5 & $2 \mathrm{mg} / \mathrm{ml}$ & $4 \mathrm{mg} / \mathrm{ml}$ & Light & Yes \\
\hline
\end{tabular}

Table 1. Details of CIA induction protocol, by experiment.

\section{Drugs}

The MAGL inhibitor JZL184 and the FAAH inhibitor PF-3845 were purchased from Cayman Chemical (Ann Arbor, MI). The $\mathrm{CB}_{1}$ antagonist rimonabant (SR141716A) and the $\mathrm{CB}_{2}$ antagonist SR144528 were generously provided to Dr. Kinsey by the National Institute on Drug Abuse (Bethesda, MD). The synthetic glucocorticoid dexamethasone (DEX) was purchased from Sigma (St Louis, MO). All drugs were prepared in a vehicle of ethanol, Cremophor (Sigma- 
Aldrich, St Louis, MO), and saline in a ratio of 1:1:18 parts. All solutions were administered at room temperature in a volume of $10 \mu \mathrm{l} / \mathrm{g}$ body weight.

\section{Experimental Plan}

The goal of the first experiment was to determine the analgesic and anti-locomotor suppression effects of acute JZL184 administration. In experiment 1a, divided into two parts, we tested a dose range of JZL184 $(1,4,8,40 \mathrm{mg} / \mathrm{kg})$ in mice subjected to CIA. Due to JZL184's potency to significantly increase brain levels of $2-A G$ at a low dose ( $4 \mathrm{mg} / \mathrm{kg})$, a JZL184 dose range was administered to determine the analgesic and anti-locomotor suppression effects of acute JZL184 treatment (Long et al., 2009). First, mice subjected to CIA were injected with a moderate $(8 \mathrm{mg} / \mathrm{kg})$ or high dose $(40 \mathrm{mg} / \mathrm{kg})$ of JZL184 (Ghosh, 2013; Kinsey et al., 2011a) or vehicle and testing for mechanical allodynia, spontaneous locomotor activity, followed by thermal hyperalgesia. Second, due to the attenuation of CIA-induced hyperalgesia in the hot plate test with the moderate and high doses of JZL184, low doses of JZL184 (1 \& $4 \mathrm{mg} / \mathrm{kg})$ (Ghosh, 2013; Kinsey et al., 2011a) or vehicle were administered to a separate cohort of mice subjected to CIA. Mice were then tested for allodynia, locomotor activity, and hyperalgesia. In experiment $1 \mathrm{~b}$ the FAAH inhibitor PF-3845 (10 mg/kg) (Ahn et al., 2009) or vehicle was administered to a separate cohort of mice subjected to CIA and mice were tested for allodynia, locomotor activity, and hyperalgesia. In experiment 1c a separate cohort of mice subjected to CIA was administered the synthetic glucocorticoid agonist dexamethasone $(2 \mathrm{mg} / \mathrm{kg}$ ) (Naidu et al., 2010) or vehicle. Mice were then tested for allodynia, locomotor activity, and hyperalgesia. PF-3845 and dexamethasone were used as positive controls. Both acute PF-3845 (10 mg/kg) (Ghosh et al., 2013) and acute dexamethasone (2 mg/kg) (Naidu et al., 2010) attenuate acute inflammatory pain. Separate control mice, not subjected to CIA, were also tested for allodynia, 
locomotor activity, and hyperalgesia in each experiment.

The goal of the second experiment was to determine the possible cannabinoid receptor mechanism of action through which JZL184 attenuated CIA-induced hyperalgesia. Mice were administered the $\mathrm{CB}_{1}$ antagonist rimonabant (3 $\mathrm{mg} / \mathrm{kg}$, i.p.), the $\mathrm{CB}_{2}$ antagonist SR144528 (3 $\mathrm{mg} / \mathrm{kg}$, i.p.), or vehicle. Thirty minutes later, mice were injected intraperitoneally with vehicle or JZL184 (40 mg/kg) and then tested for allodynia, locomotor activity, and hyperalgesia. Separate control mice, not subjected to CIA, were also tested for allodynia, locomotor activity, and hyperalgesia.

The goal of the third experiment was to determine the anti-inflammatory and antinociceptive effects of chronic JZL184 administration. Chronic PF-3845 administration was used as a positive control (Kinsey et al., 2011a). The day that mice received the booster injection of collagen (i.e., day 21), mice were administered JZL184 (8 mg/kg, s.c.), PF-3845 (10 mg/kg, s.c.), or vehicle once daily, for 15 consecutive days. During chronic administration mice were assessed daily for gross signs of inflammation using paw swelling and clinical scores as described above. After the final treatment with JZL184, PF-3845, or vehicle (i.e., day 36), each mouse was tested for locomotor activity, allodynia, and hyperalgesia, as detailed below. Separate control mice, not subjected to CIA, were also administered vehicle repeatedly and tested for allodynia, locomotor activity, and hyperalgesia.

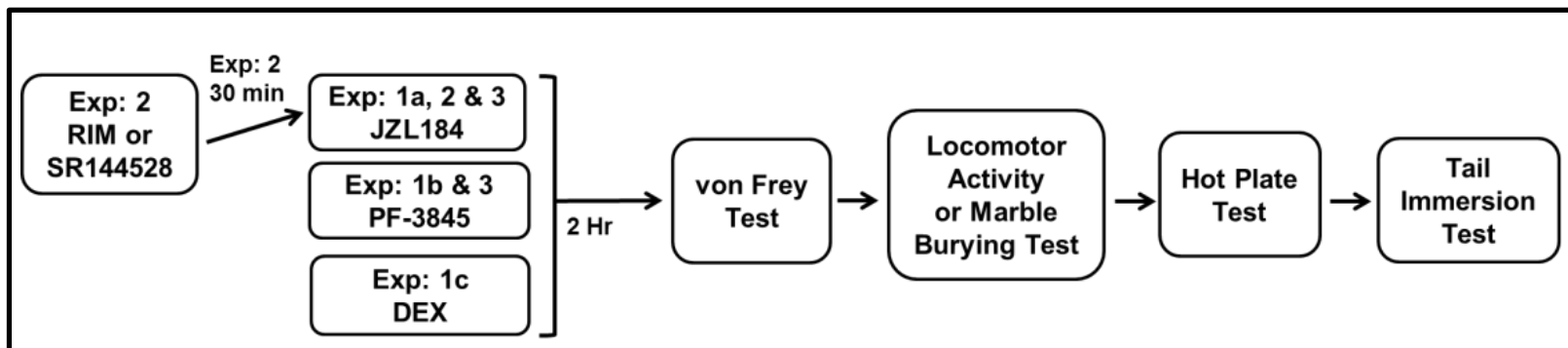

Figure 2. Diagram of behavioral test battery. In each experiment, mice were administered drug or vehicle and tested $2 \mathrm{~h}$ later for mechanical allodynia in the von Frey assay, a locomotor assay, and thermal hyperalgesia in the hot plate and tail immersion assays. In Experiment 2 mice were administered cannabinoid receptor antagonists or vehicle $30 \mathrm{~min}$ before JZL184. 


\section{Behavioral Assessments}

Behavioral testing (allodynia, locomotor activity, and hyperalgesia) began after the development of inflammation in at least 1 paw (approximately 7-14 days after the "booster" injection of collagen). Mice were randomly assigned to a drug treatment and tested by an experimenter who was blinded to the treatment conditions. Due to ongoing model development separate cohorts of mice were used for each experiment (see Table 1). In the case where multiple experimenters were required, interobserver reliabilities for behavioral tests were performed before the experiments were conducted and were correlated to $>0.98$. Mice were tested on all behavioral assays in one day. For experiments with JZL184 and PF-3845, significant increases in endocannabinoid tissue levels are present $24 \mathrm{~h}$ after administration of either compound (Ahn et al., 2009; Long et al., 2009). Dexamethasone is long acting steroid with a biological half-life of 36 - 54 h (Ozdemir, Guvenal, Cetin, Kaya, \& Cetin, 2003). The test battery was performed in the following order, based on the level of stress each test induces in mice, to decrease the effects of stress on behavior: mechanical allodynia, locomotor activity, hot plate test, and tail immersion test (see Figure 2). Although mechanical allodynia is more stressful than locomotor activity it was performed first because mice were required to acclimate for at least 60 min on the von Frey testing apparatus (Kinsey et al., 2009). Performing mechanical allodynia first minimized the time between drug administration and the last behavior assay.

On the test day, mice were brought into the testing room, weighed, and injected. After receiving drug, the mice were placed in ventilated polycarbonate chambers $(7.5 \times 9 \mathrm{~cm})$ on an aluminum mesh table, where they were allowed to acclimate for $120 \mathrm{~min}$ before testing for 
mechanical allodynia, as detailed below. Then mice were individually placed into either a clean, plastic test cage to test spontaneous locomotor activity or a test cage filled with bedding and evenly spaced marbles to test locomotor activity using the marble burying test. Mice habituated to the plastic test cages, but not the test cages with bedding and evenly spaced marbles (Thomas et al., 2009). Therefore, for experiments where mice were repeatedly tested the marble burying test was used to measure locomotor activity. Immediately following locomotor activity, hyperalgesia response latencies were assessed in the hotplate and then tail immersion tests as detailed below (see Figure 2). Thus, for JZL184, PF-3845, and dexamethasone, the total absorption time before behavioral testing was 120 min across treatments. A 120 min absorption time for JZL184 was used based on previous reports that the endocannabinoid 2-AG tissue levels peak $2 \mathrm{~h}$ after administration of the compound (Long et al., 2009). A $120 \mathrm{~min}$ absorption time for PF-3845 and dexamethasone was used to keep testing consistent across experiments. For the receptor mechanism study, mice were pretreated with the $\mathrm{CB}_{1}$ receptor antagonist rimonabant (3 $\mathrm{mg} / \mathrm{kg}$, i.p.), the $\mathrm{CB}_{2}$ receptor antagonist SR144528 (3 mg/kg, i.p.), or vehicle $30 \mathrm{~min}$ before receiving JZL184. The effects of the $\mathrm{CB}_{1}$ and $\mathrm{CB}_{2}$ receptors are blocked by a $3 \mathrm{mg} / \mathrm{kg}$ dose of rimonabant and SR144528, respectively with a 30 min pretreatment time (Lichtman, Sheltona, Advania, Cravatt, 2004). For the chronic dosing study, a separate cohort of mice was randomly assigned to drug treatment and administered JZL184 (8 mg/kg, s.c.), PF-3845 (10 mg/kg, s.c.), or vehicle once daily for 15 consecutive days, starting 21 days after the initial immunization. Based on preliminary data from our lab and previous literature we chose moderate doses of JZL184 and PF-3845 that attenuate inflammation and pain without the development of tolerance with repeated administration (Kinsey et al., 2013; Schlosburg et al., 2010). Behavioral testing was conducted on the last day of chronic dosing (i.e., day 15). The chronic dosing timeline was 
chosen based on the analgesic and anti-inflammatory effects of chronic FAAH inhibition in mice subjected to CIA (Kinsey et al., 2011a).

Mechanical allodynia test: Mechanical allodynia was tested using the "up-down" method (Chaplan, Bach, Pogrel, Chung, \& Yaksh, 1994; Kinsey et al., 2009) with von Frey filaments (North Coast Medical, Morgan Hill, CA) to stimulate the plantar surface of each hind paw. Von Frey filaments are commonly used to test touch sensitivity in humans and other animals and are calibrated to bend at established weights. Each hind paw was stimulated approximately twice per second with each filament $(0.16-6.0 \mathrm{~g})$ five times starting with the $0.6-\mathrm{g}$ filament. The filaments were tested in ascending order until the mouse clutched or lifted its paw. This was considered a positive response. Once the mouse responded positively to 3 out of 5 presentations of the filament, the filaments were presented in descending order to establish a sensory threshold.

CIA-suppressed locomotor test: In addition to eliciting behavioral responses, pain can also suppress normal behaviors, such as locomotion. Thus, to complement the nociceptive tests, the total distance travelled and the total time spent immobile were also assessed, as described previously (Kinsey, O’Neal, Long, Cravatt, \& Lichtman, 2011c). Approximately 45 min after the von Frey test, mice were placed individually into a clean, plastic test cage $(30.80 \mathrm{~cm} \mathrm{x} 40.60 \mathrm{~cm}$ $\mathrm{x} 15.88 \mathrm{~cm}$ ), inside of a sound-attenuating chamber, and spontaneous locomotor activity was recorded for 20 minutes, using ANYmaze automated video tracking software (Stoelting, Wool Dale, IL).

Marble Burying test. The marble burying test is a useful test of locomotor suppression in the chronic constriction injury mouse model of neuropathic pain (J. Wilkerson, personal communication, January 22, 2014). Unlike the spontaneous locomotor test detailed above, mice 
do not habituate to the marble burying test (Thomas et al., 2009). Therefore, the marble burying test was used in place of spontaneous locomotor activity to measure locomotor suppression for all experiments in which mice were repeatedly tested. In the marble burying test, mice were placed individually into a plastic test cage $(30.80 \mathrm{~cm} \times 40.60 \mathrm{~cm} \times 15.88 \mathrm{~cm})$ filled to a depth of $5 \mathrm{~cm}$ with SANI-CHIP Aspen bedding (Harlan Laboratories, Indianapolis, IN) with 25 clear, glass marbles (10mm in diameter) arranged in an evenly spaced, 5 x 5 grid-like pattern across the surface of the bedding. The cage was placed inside of a sound-attenuating chamber and locomotor activity was recorded for 20 minutes, using ANYmaze automated video tracking software (Stoelting, Wool Dale, IL). In experiments where locomotor activity was measured using the marble burying test, the amount of marbles buried was also assessed. Mice placed in the marble burying test apparatus engage in a repetitive digging behavior that leads to marble s being buried (Thomas et al., 2009).

Nociceptive tests. Mice were tested for thermal hyperalgesia using the hot plate and tail immersion tests approximately $1 \mathrm{~h}$ after testing locomotor suppression. Individual mice were placed in a ventilated polycarbonate chamber on a hot plate that was heated to $52^{\circ} \mathrm{C}$ (Kinsey et al., 2011a; Naidu et al., 2010). The latency for each mouse to lick or shake a hind paw, to flare its toes, or to jump out of the apparatus, was scored as the dependent variable. Based on preliminary data from our lab and previous literature a 30 s cutoff time was used to avoid the possibility of tissue damage (Kinsey et al., 2011a). Immediately after the hot plate test, individual mice were placed head first into a small bag assembled from absorbent under pads, leaving the tail exposed (Kinsey et al., 2011a). The mouse was gently held while the distal $1 \mathrm{~cm}$ of the tail was quickly dipped into a water bath heated to $52^{\circ} \mathrm{C}$. The latency for the mouse to withdraw its tail was scored as the dependent variable. Because water transfers heat quicker than 
a solid surface, a shorter cutoff time of $10 \mathrm{~s}$ based on previous literature was used to avoid the possibility of tissue damage (Kinsey et al., 2011a). 


\section{Statistical Analyses}

All data were analyzed by ANOVA, followed by Bonferroni post hoc, with the exception of the dose response data, for which Dunnett's post hoc was used instead (all doses compared with vehicle or non-CIA control group). For the first experiment, a one-way ANOVA of acute drug condition was calculated. For the second experiment, a one-way ANOVA of drug doses (MAGL inhibitor and CB receptor antagonist) was conducted. The third experiment was analyzed using a one-way ANOVA of drug doses. Differences were considered statistically significant if $\mathrm{p}<0.05$.

\section{Results}

\section{Experiment 1a: Acute MAGL inhibitor JZL184 attenuates CIA-induced thermal hyperalgesia and did not affect CIA-suppressed locomotor activity at high and moderate doses}

Based on preliminary data from our lab and previous literature we first tested a moderate and high dose of JZL184 that we expected would attenuate hyperalgesia (Ghosh et al., 2013; Kinsey et al., 2011a). Mice were subjected to CIA (see Table 1). Eighteen percent of mice subjected to CIA developed significantly higher clinical scores than non-CIA controls $[\mathrm{F}(1,38)$ $=128.6 ; \mathrm{p}<.0001 ;$ Figure 3A]. Although it is expect that some mice would not respond to the CIA treatment, the incidence in this cohort was low, based on previous literature (Brand et al., 2007). On test day, mice were injected with the MAGL inhibitor JZL184 (8 \& $40 \mathrm{mg} / \mathrm{kg}$, i.p.) or vehicle. Behavioral assays were performed $2 \mathrm{~h}$ after JZL184 administration, to coincide with peak tissue levels of 2-AG (Long et al., 2009). Acute JZL184 attenuated CIA-induced thermal hyperalgesia in the hot plate test $[\mathrm{F}(3,58)=9.3 ; \mathrm{p}<.0001$; Figure 3B $]$. Post hoc comparisons 
revealed that JZL184 significantly reduced hyperalgesia in the hot plate test at both the $8 \mathrm{mg} / \mathrm{kg}$ $(\mathrm{p}<.05)$ and $40 \mathrm{mg} / \mathrm{kg}(\mathrm{p}<.01)$ doses. In the tail immersion test, there was a main effect of drug treatment on thermal hyperalgesia $[\mathrm{F}(3,58)=3.04 ; \mathrm{p}<.05$; Figure 3C $]$. However, post-hoc comparisons revealed that CIA did not significantly increase tail withdrawal times, compared to controls $(\mathrm{p}=.06)$. Therefore, it is not surprising that acute JZL184 did not affect thermal hyperalgesia in the tail immersion test at either the $8 \mathrm{mg} / \mathrm{kg}(\mathrm{p}=.99)$ or $40 \mathrm{mg} / \mathrm{kg}(\mathrm{p}=1)$ dose.

For the von Frey test, there was a main effect of drug treatment on mechanical allodynia $[\mathrm{F}(3,120)=2.95 ; \mathrm{p}<.05 ;$ Figure 3D $]$ when both paws were analyzed together. However, posthoc comparisons revealed that CIA did not significantly increase mechanical allodynia $(\mathrm{p}=.09)$ compared to controls. Due to the lack of CIA effect, acute JZL184 did not restore mechanical allodynia in CIA mice at the $8 \mathrm{mg} / \mathrm{kg}(\mathrm{p}=1)$ or $40 \mathrm{mg} / \mathrm{kg}(\mathrm{p}=.91)$ dose. When analyzed separately, there was no significant difference in mechanical allodynia in the left paws [F (3, $120)=2.23 ; \mathrm{p}=.09]$ or right paws $[\mathrm{F}(3,120)=1.53 ; \mathrm{p}=.22]$.

CIA significantly suppressed locomotor activity $[\mathrm{F}(3,1236)=141.3 ; \mathrm{p}<.0001$; Figure 3E]. However, post-hoc comparisons revealed no significant attenuation of locomotor suppression by acute JZL184 at the $8 \mathrm{mg} / \mathrm{kg}$ dose $(\mathrm{p}=.96)$ or the $40 \mathrm{mg} / \mathrm{kg}$ dose $(\mathrm{p}=.22)$.

Due to the attenuation of CIA-induced hyperalgesia by a high and moderate dose of acute JZL184 (8 \& $40 \mathrm{mg} / \mathrm{kg}$ ) we next tested lower (1 \& $4 \mathrm{mg} / \mathrm{kg})$ doses of JZL184 to establish a dose response. However, the data was not combined into a single analysis because of difference in methodology (e.g. differences in CIA induction and locomotor assay performed). A low dose (4 $\mathrm{mg} / \mathrm{kg}$ ) of JZL184 attenuates allodynia in an acute inflammatory pain model (Ghosh et al., 2013), but does not reduce marble burying (Kinsey, O'Neal, Long, Cravatt, \& Lichtman, 2011c). Therefore, JZL184 (1 mg/kg) was also used as a subthreshold dose to establish the dose response 
(Ghosh et al., 2013; Kinsey et al., 2011c). Due to the low incidence of arthritis in the previous experiment, a separate cohort of mice was subjected to CIA (see Table 1). Thirty-eight percent of the mice subjected to CIA developed significantly higher clinical scores than non-CIA controls $[\mathrm{F}(2,57)=38.4 ; \mathrm{p}<.0001 ;$ Figure 4A $]$. Although the incidence of arthritis was higher than the previous experiment, the incidence in this cohort was lower than expected, based on the literature (Brand et al., 2007). On test day, mice were injected with the MAGL inhibitor JZL184 $(1,4 \mathrm{mg} / \mathrm{kg})$, or vehicle. Two h later behavioral assays were performed. CIA did not induce thermal hyperalgesia $[F(3,74)=1.79 ; p=.16$; Figure $4 B]$ in the hot plate test. Therefore, acute JZL184 had no effect. CIA did induce hyperalgesia in the tail immersion test $[\mathrm{F}(3,74)=5.11 ; \mathrm{p}$ $<.01$; Figure 4C]. However, post-hoc comparisons revealed no significant attenuation of hyperalgesia of acute JZL184 at the $1 \mathrm{mg} / \mathrm{kg}$ or the $4 \mathrm{mg} / \mathrm{kg}$ dose.

CIA induced mechanical allodynia when both paws were analyzed together $[\mathrm{F}(3,88)=$ 10.46; $\mathrm{p}<.0001$; Figure 4D], but post-hoc comparisons revealed there was no significant decrease of allodynia by acute JZL184 at the $1 \mathrm{mg} / \mathrm{kg}$ or $4 \mathrm{mg} / \mathrm{kg}$ dose. When paws were analyzed separately, there was a significant difference in mechanical allodynia in the right paws $[\mathrm{F}(3,40)=7.11 ; \mathrm{p}<.01]$, and the left paws $[\mathrm{F}(3,40)=4.36 ; \mathrm{p}<.05]$. Post-hoc comparisons revealed there was no significant decrease of allodynia in CIA mice in the right paw or the left paw at either the $1 \mathrm{mg} / \mathrm{kg}$ or $4 \mathrm{mg} / \mathrm{kg}$ dose.

CIA reduced marbles buried $[\mathrm{F}(3,62)=8.193 ; \mathrm{p}<.001 ;$ Figure 4E], but post-hoc comparisons revealed no significant restoration of marbles buried at the $1 \mathrm{mg} / \mathrm{kg}$ or $4 \mathrm{mg} / \mathrm{kg}$ dose of acute JZL184. CIA did not suppress locomotor activity in the marble burying test $[\mathrm{F}(3,62)$ $=.745 ; \mathrm{p}=.53 ;$ Figure 4F]. Due to the lack of CIA effect, post-hoc comparisons revealed no significant attenuation of locomotor suppression by acute JZL184. 


\section{Experiment 1b: Acute FAAH inhibitor PF-3845 does not affect CIA-induced thermal hyperalgesia or CIA-suppressed locomotor activity}

In the next experiment, we tested the FAAH inhibitor PF-3845 to compare to JZL184 as a positive control. FAAH inhibition was expected to attenuate CIA-induced hyperalgesia based on previous literature (Kinsey et al., 2011a). We chose the dose of PF-3845 administered in the present study based on the attenuation of allodynia by acute PF-3845 (10 mg/kg) administration in the mouse carrageenan model of acute inflammatory pain (Ghosh et al., 2013). A separate cohort of mice was subjected to CIA because of the low incidence of arthritis in the acute JZL184 experiments (see Table 1). Ninety percent of the mice developed significantly higher clinical scores than non-CIA controls $[\mathrm{F}(2,47)=22.96 ; \mathrm{p}<.0001$; Figure 5A $]$, as expected. On test day, mice were injected with the FAAH inhibitor PF-3845, or vehicle. To keep methods consistent as possible despite model development behavioral assays were performed $2 \mathrm{~h}$ later. CIA did not induce thermal hyperalgesia in the hot plate $[\mathrm{F}(2,29)=.66 ; \mathrm{p}=.52$; Figure 5B $]$ and tail immersion tests $[\mathrm{F}(2,29)=.52 ; \mathrm{p}=.60$; Figure $5 \mathrm{C}]$. Therefore, acute PF-3845 had no effect in the hot plate or tail immersion tests.

CIA induced mechanical allodynia when both paws were analyzed together $[\mathrm{F}(2,61)=$ 5.32; $\mathrm{p}<.01$; Figure 5D] but, post-hoc comparisons revealed that acute PF-3845 did not significantly decrease allodynia. When analyzed separately, there was not a significant difference in mechanical allodynia in the right paws $[\mathrm{F}(2,29)=2.07 ; \mathrm{p}=.14]$ or the left paws $[\mathrm{F}(2,29)=$ $3.06 ; \mathrm{p}=.06]$.

CIA did not reduce marbles buried $[\mathrm{F}(2,24)=3.15 ; \mathrm{p}=.06$; Figure 5E $]$. PF-3845 had no effect on the number of marbles buried. However, there was a main effect of drug treatment on locomotor activity in the marble burying test $[\mathrm{F}(2,29)=5.99 ; \mathrm{p}<.01$; Figure 5F $]$, but post- 
hoc comparisons revealed no CIA-suppressed locomotor activity. PF-3845 had no effect on locomotor activity.

\section{Experiment 1c: Acute dexamethasone does not affect CIA-induced thermal hyperalgesia or CIA-suppressed locomotor activity}

Due to the inconsistencies in the behavioral effects with the administration of acute PF3845 we next tested the steroid dexamethasone as an alternative positive control. Acute dexamethasone $(2 \mathrm{mg} / \mathrm{kg})$ attenuates hyperalgesia in the mouse LPS model of acute inflammatory pain (Naidu et al., 2010). A separate cohort of mice was subjected to CIA, because of the inconsistencies in behavioral effects between CIA and control mice in the previous experiments (see Table 1). Seventy-seven percent of the mice developed significantly higher clinical scores than non-CIA controls $[\mathrm{F}(2,26)=17.4 ; \mathrm{p}<.0001$; Figure 6A $]$. On test day, mice were injected with the glucocorticoid dexamethasone $(2 \mathrm{mg} / \mathrm{kg})$, or vehicle. Behavioral assays were performed $2 \mathrm{~h}$ later. CIA did not induce thermal hyperalgesia in the hot plate $[\mathrm{F}(2,21)=$ $.72 ; \mathrm{p}=.50$; Figure 6B $]$ and tail immersion tests $[\mathrm{F}(2,21)=1.43 ; \mathrm{p}=.26$; Figure 6C $]$. Acute dexamethasone had no effect in either test.

CIA did not induced mechanical allodynia when both paws were analyzed together $[\mathrm{F}(2$, $45)=.31 ; p=.73 ;$ Figure 6D]. Due to the lack of CIA effect, acute dexamethasone did not reverse mechanical allodynia. This lack of significant difference in mechanical allodynia was maintained when paws were analyzed separately in the right paws $[\mathrm{F}(2,21)=.15 ; \mathrm{p}=.86]$ or the left paws $[\mathrm{F}(2,21)=.15 ; \mathrm{p}=.86]$.

CIA reduced marbles buried $[\mathrm{F}(2,21)=4.67 ; \mathrm{p}<.05$; Figure $6 \mathrm{E}]$, but post-hoc comparisons revealed no significant effect of dexamethasone. CIA mice did not display 
locomotor suppression in the marble burying test $[\mathrm{F}(2,21)=.427 ; \mathrm{p}=.66$; Figure $6 \mathrm{~F}]$. Acute dexamethasone had no effect on locomotor activity in the marble burying test.

\section{Experiment 2: Receptor mechanism of action of MAGL inhibition by JZL184 attenuation} of CIA-induced hyperalgesia is unclear

In the next experiment, we tested the cannabinoid receptor mechanism of action of the high dose of JZL184 (40 mg/kg) in attenuating CIA-induced hyperalgesia, per the results of the first experiment. Again, due to inconsistencies in the CIA effects compared to controls in the previous experiments, a separate cohort of mice was subjected to CIA (see Table 1). Sixty-six percent of the mice subjected to CIA developed significantly higher clinical scores than non-CIA controls $[\mathrm{F}(2,87)=73.01 ; \mathrm{p}<.0001 ;$ Figure 7A $]$. In order to assess the receptor mechanism of action underlying the antihyperalgesic effects of acute JZL184 (40 mg/kg), mice were pretreated with the selective $\mathrm{CB}_{1}$ antagonist rimonabant ( $3 \mathrm{mg} / \mathrm{kg}$ ), the selective $\mathrm{CB}_{2}$ antagonist SR144528 ( $3 \mathrm{mg} / \mathrm{kg}$ ), or vehicle $30 \mathrm{~min}$ before receiving JZL184. The dosing and pre-treatment times of the cannabinoid receptor agonists was chosen based on previous literature (Lichtman et al., 2004). CIA did not induce thermal hyperalgesia in the hot plate test $[\mathrm{F}(4,55)=.31 ; \mathrm{p}=.87$; Figure 7B]. Due to the lack of CIA effect, neither JZL184 nor the antagonists had any effect in the hot plate test. There was a main effect of drug treatment in the tail immersion test $[\mathrm{F}(4,55)=3.98 ; \mathrm{p}$ $<.05$; Figure 7C], but post-hoc comparison revealed that CIA did not induce thermal hyperalgesia in the tail immersion test. However, in the tail immersion test JZL184 increased tail withdrawal latency in CIA mice. The increase by JZL184 was not reversed by rimonabant or SR144528.

CIA induced mechanical allodynia $[\mathrm{F}(4,55)=14.65 ; \mathrm{p}<.0001$; Figure 7D $]$ when both paws were analyzed together. Post-hoc comparisons revealed that JZL184 (40 mg/kg) did not 
restore allodynia. When analyzed separately, there was a significant difference in mechanical allodynia in the right paws $[\mathrm{F}(4,55)=7.54 ; \mathrm{p}<.0001]$, but not the left paws $[\mathrm{F}(4,55)=2.14 ; \mathrm{p}$ $=.09]$.

CIA reduced marbles buried $[\mathrm{F}(4,55)=18.77 ; \mathrm{p}<.0001$; Figure 7E $]$. However, posthoc comparisons revealed an additional decrease in marbles buried caused by acute JZL184 (40 $\mathrm{mg} / \mathrm{kg}$ ) that was not blocked by rimonabant or SR144528. This decrease in marble burying was in line with published effects of this high dose of JZL184 in marble burying (Kinsey et al., 2011c). There was a main effect of drug treatment in locomotor activity in the marble burying test $[\mathrm{F}(4,55)=7.820 ; \mathrm{p}<.0001 ;$ Figure $7 \mathbf{F}]$, that was driven by JZL184 $(40 \mathrm{mg} / \mathrm{kg})$ and was not reversed by rimonabant or SR144528.

\section{Experiment 3: Chronic MAGL or FAAH inhibition does not affect CIA-induced hyperalgesia or inflammation}

We next tested the effects of chronic MAGL and FAAH inhibition. Chronic MAGL and FAAH inhibition attenuates inflammation (Kinsey et al.,2011a; Kinsey et al.,2011b). Therefore, we hypothesized that attenuating inflammation would improve behavioral outcomes in CIA mice. A separate cohort of mice was subjected to CIA (see Table 1). Ninety-eight of mice subjected to CIA developed significantly higher clinical scores than non-CIA controls $[\mathrm{F}(3,43)$ $=5.596 ; p=.0025 ;$ Figure 8A]. However, post-hoc comparisons revealed no significant difference in clinical scores with drug treatment. Mice were administered the MAGL inhibitor JZL184 (8 mg/kg, s.c.), the FAAH inhibitor PF-3845 (10 mg/kg, s.c.), or vehicle once daily for 15 consecutive days. Drug administration started on "booster" collagen exposure day (21 days after the initial immunization; Kinsey et al., 2011a). Repeated administration of moderate doses 
of JZL184 (8 mg/kg) (Kinsey et al., 2013) or PF-3845 (10 mg/kg) (Schlosburg et al., 2010) maintains anti-allodynic effects in a mouse model of neuropathic pain for 5 and 6 days, respectively. On day 15, mice were injected again, and behavioral assays were performed $2 \mathrm{~h}$ later.

CIA did not induce thermal hyperalgesia in the hot plate $[\mathrm{F}(3,44)=.18 ; \mathrm{p}=.91$; Figure 8B $]$ or tail immersion test $[\mathrm{F}(3,44)=.28 ; \mathrm{p}=.84$; Figure 8C $]$. Neither chronic PF-3845 nor JZL184 had any effect on hyperalgesia.

CIA mice did not display mechanical allodynia, compared to control mice $[\mathrm{F}(3,44)=$ 2.569; $\mathrm{p}=.06 ;$ Figure 8D] when both paws were analyzed together. When analyzed separately, there was a main effect of drug treatment on mechanical allodynia in the left paws $[\mathrm{F}(3,44)=$ $3.232 ; \mathrm{p}<.03]$, but not the right paws $[\mathrm{F}(3,44)=.552 ; \mathrm{p}<.65]$ of mice. However, post-hoc comparisons revealed that CIA did not induce mechanical allodynia in the left paw. PF-3845 and JZL184 had no effect on allodynia.

There was a main effect of suppressed locomotor activity in the spontaneous locomotor activity test $[\mathrm{F}(3,44)=4.32 ; \mathrm{p}<.01$; Figure 8E]. Surprisingly, post-hoc comparisons revealed chronic JZL184 suppressed locomotor activity in CIA mice, compared to vehicle treated control mice.

\section{Discussion}

The goal of this study was to test the hypothesis that inhibition of MAGL would decrease hyperalgesia and locomotor suppression in mice subjected to collagen induced arthritis (CIA). Acute administration of the selective MAGL inhibitor JZL184 (8 \& $40 \mathrm{mg} / \mathrm{kg}$ ) attenuated CIAinduced thermal hyperalgesia in the hot plate test, but not the tail immersion test. JZL184 (8 \& $40 \mathrm{mg} / \mathrm{kg}$ ) did not reverse CIA-induced locomotor suppression or affect mechanical allodynia. 
Conversely, acute administration of the selective FAAH inhibitor PF-3845, the selective MAGL inhibitor JZL184 (1\& $4 \mathrm{mg} / \mathrm{kg})$, or the glucocorticoid dexamethasone did not significantly affect any of our outcome measures.

The second objective of this study was to determine cannabinoid receptor involvement in the attenuation of CIA-induced hyperalgesia by acute JZL184 administration. There was insufficient CIA induction of hyperalgesia or locomotor suppression to determine cannabinoid receptor involvement in acute JZL184 attenuation of CIA-induced hyperalgesia. In the tail immersion test, acute JZL184 administration increased the latency to respond in the CIA-treated mice, but neither the $\mathrm{CB}_{1}$ receptor antagonist rimonabant nor the $\mathrm{CB}_{2}$ receptor antagonist SR144528 reversed the effect of JZL184. CIA induced mechanical allodynia that was not restored by acute JZL184. Similarly, CIA reduced the number of marbles buried, and this reduction was unaffected by acute JZL184.

The third objective of this study was to evaluate the effects of chronic administration of the selective MAGL inhibitor JZL184 and the selective FAAH inhibitor PF-3845 in CIA-induced hyperalgesia, allodynia, and locomotor suppression. There was insufficient CIA induction of hyperalgesia, allodynia, or locomotor suppression on the behavioral test day to determine the effects of chronic dosing.

The present study is the first to show that acute MAGL inhibition reduces thermal hyperalgesia in a mouse model of inflammatory arthritis. The reduction of inflammatory pain by acute MAGL inhibition is consistent with previous reports that the MAGL inhibitors JZL184 and KML29 attenuate carrageenan-induced acute inflammatory pain (Gosh et al., 2013; IgnatowskaJankowska et al., 2013). These studies, taken together with the present data, suggest that acute MAGL inhibition reduces both chronic and acute inflammatory pain. 
However, there are inconsistencies with the reduction in pain elicited by acute MAGL inhibition in the present study. One potential reason for the inconsistency in results is the problems experienced with CIA model itself. As detailed in Table 1, the CIA model was still being optimized throughout the present studies. After the initial CIA immunization, it typically took 4-8 weeks for the mice to develop arthritis. CIA induction normally results in $80-100 \%$ of mice developing arthritis in at least one paw (Brand et al., 2007). In the present study, less than $50 \%$ of the mice developed CIA in the first few cohorts. The mice in these cohorts were used to test acute JZL184 ( $8 \& 4 \mathrm{mg} / \mathrm{kg}$ ) to make progress on this thesis while continuing with model development. Therefore, changes were made to increase the concentration of bacteria and heaviness of the CFA oils in each successive cohort of mice. In addition, seemingly minor adjustments to the methodology, such as using a stopcock to minimize the introduction of air in the emulsion when drawing into the syringe, turned out to be very important. This methodological fine tuning resulted in an arthritic incidence rate of over $90 \%$. However, the CIA was more extreme, and with a more rapid onset than in previous cohorts of mice, and may have contributed to the lack of an anti-inflammatory effect in the chronic dosing study (thus not replicating previously published reports), which was run later than the acute JZL184 studies. Moreover, the concern now is that the CIA no longer reflects human inflammatory arthritis. Model development is still in progress, with the goal of finding the optimal concentration and consistency of CFA to induce a consistently high incidence of arthritis, and we continue to correspond with helpful consultants as we troubleshoot the model. After optimizing the CIA model, the next step will be to replicate the present studies, with the goal of obtaining more consistent, and potentially publishable, results. If nothing else, the inconsistency of the CIA 
model in the present study taught me that careful planning and preparation do not necessarily translate into research proceeding according to plan.

JZL184 attenuated CIA-induced pain in some experiments but not others, and depended on the pain assay. On the hot plate test, acute JZL184 (8 \& $40 \mathrm{mg} / \mathrm{kg})$ attenuated hyperalgesia. Although these results did not repeat in the receptor mechanism experiment, acute JZL184 (40 $\mathrm{mg} / \mathrm{kg}$ ) did reduce CIA-induced hyperalgesia in pilot groups of mice (please see Appendix A). This inconsistency is plausibly due to the use of the highly virulent CIA that was induced when testing receptor mechanisms. Thus, because of their highly inflamed and calcified joints, the mice may have had a difficult time licking or shaking their hind paws to indicate hyperalgesia. In support of this idea, CIA mice did not display increased hyperalgesia in any assay of the receptor mechanism study. In my current work, I am exploring other dependent variables that may help get at joint function, such as locomotor coordination in the rotarod test, as well as more localized pain tests, such as the acetone-induced cold allodynia test and the Hargreaves plantar stimulator test.

Similarly, although the tail immersion test is also an assay of thermal hyperalgesia, there was no significant effect of JZL184, and even the CIA effect was inconsistent. This lack of an effect could be due to the differences in the neural pathways. The hot plate test measures a supraspinal response; whereas the tail immersion test measures a spinal reflex (Le Bars, Gozariu, \& Cadden, 2001). JZL184 also failed to attenuate CIA-induced mechanical allodynia in the von Frey test. Inflammation may not develop in all four paws of a CIA-induce mouse (Brand, 2007). Therefore, in the present study inflammation was not present in every hind paw even though all of the mice tested in the acute dosing experiments developed CIA symptoms. In the von Frey test 
the threshold for both hind paws was measured. Therefore, inconsistent inflammation could be a reason why mechanical allodynia was not present across all experiments.

Many patients experiencing chronic pain, such as those with rheumatoid arthritis (RA) have problems with mobility (Laroche, Poxxo, Ornetti, Tavernier, \& Maillefert, 2006). As in humans, CIA induced locomotor suppression in the present study. Because mice quickly habituate to the spontaneous locomotor activity test, the marble burying test was used to measure locomotor activity for the latter experiments in the present study. CIA did not reliability suppress locomotor activity, and so it is not surprising that JZL184 was unable to reverse this lack of locomotor suppression in the marble burying test. However, locomotor activity may have been confounded by the order of the behavioral assays. The von Frey test requires mice to acclimate for 60 min a wire mesh apparatus before testing (Kinsey et al., 2009). Therefore, in the present study the von Frey test was performed prior to locomotor activity to minimize time between drug administration and the last behavioral assay. It is possible that standing on the wire mesh and stimulation of hind paws with the von Frey filaments affected the locomotor activity of the mice. In the future we plan on assessing locomotor activity first to limit confounds. An alternative is to test motor coordination, which may grant some insights into loss of motor function as a result of CIA. The rotarod is a test of motor coordination where a mouse is placed on a rotating rod and the latency to fall off the rod is measured (Kinsey et al., 2011d). Drugs that affect motor coordination, such as ethanol and THC, significantly reduce the latency to fall from the rotarod. Since running the present studies, my lab purchased a rotarod, and I have found that CIA mice spend less time on the rotarod at a fixed speed (please see Appendix B).

The finding in the present study that the $\mathrm{CB}_{1}$ receptor antagonist rimonabant or the $\mathrm{CB}_{2}$ receptor antagonist SR144528 did not reverse the effects of JZL184 is most likely due to 
inconsistencies with the CIA model in the present study. Indeed, there was not a significant difference between the CIA and control mice used to test cannabinoid receptor mechanisms in hyperalgesia and locomotor activity. An alternative, albeit less plausible explain for the lack of JZL184 reversal is a non-cannabinoid mechanism of action. In CIA mice JZL184 did increase the latency of mice to withdraw their tails from the water compared to vehicle in the tail immersion test. However, neither the $\mathrm{CB}_{1}$ nor the $\mathrm{CB}_{2}$ receptor antagonist reversed the JZL184 increase in latency. In addition to $\mathrm{CB} 1$ and $\mathrm{CB} 2$ receptors cannabinoids will also bind to other receptors such as the orphan G protein-coupled receptor GPR55, transient receptor potential vanilloid receptor (TRPV1), and peroxisome proliferator-activated receptors (PPAR) (Howlett, 2002). However, JZL184 attenuates allodynia in the carrageenan model of acute inflammatory pain through a mechanism that requires both $\mathrm{CB}_{1}$ and $\mathrm{CB}_{2}$ receptors (Gosh, 2013), indicating that JZL184 modulation of inflammatory pain likely occurs through a cannabinoid receptor mechanism. I predict that, in my future studies, JZL184 will attenuate pain in a chronic model of inflammatory pain through a similar mechanism of action.

Based on the observation that acute MAGL inhibition with JZL184 (40 mg/kg) attenuated thermal hyperalgesia on the hot plate test; it was surprising that chronic JZL184 did not attenuate CIA-induced thermal hyperalgesia. As with the antagonist study, the inconsistencies between acute and chronic dosing of JZL184 in attenuating thermal hyperalgesia may be due to the use of the more virulent CIA. Again, the mice appeared to have difficulty licking or shaking their hind paws, both of which are dependent variables that we operationally defined to indicate hyperalgesia. In support of this idea, the CIA mice did not display increased hyperalgesia. Another possible contributing factor is that chronic JZL184 administration started too late to attenuate CIA induced hyperalgesia. In other words, the mice may have started developing 
arthritis before they received any drug. Chronic dosing was started on day 21 after the initial immunization, but mice started developing swelling and paw inflammation only a few days after chronic JZL184 dosing started. A third possible explanation is that mice developed tolerance to chronic JZL184 administration. Repeated administration of high doses of JZL184 (16 \& 40 $\mathrm{mg} / \mathrm{kg}$ ) reduced its anti-allodynic effects after 5 days in a mouse model of neuropathic pain (Kinsey et al., 2013; Schlosburg et al., 2010). Although the low dose of JZL184 (8 mg/kg) used in the present study did not show tolerance in the previous reports, the effects of a 15 day treatment of JZL184 are unknown. A possible solution to the problem of JZL184 tolerance would be to use a lower dose of JZL184 or to genetically delete MAGL. MAGL (-/-) mice are not yet commercially available, although my advisor, Dr. Kinsey, has received notice from Dr. Benjamin Cravatt, who designed these mice, that he will make breeders available to my lab, as needed.

The observation that neither acute nor chronic FAAH inhibition affected hyperalgesia in mice subjected to CIA was surprising, because chronic administration of the FAAH inhibitor URB597 or genetic deletion of FAAH attenuated CIA-induced hyperalgesia in the hot plate and tail immersion tests (Kinsey et al., 2011a). One possible explanation of the disparities between the current findings and those by Kinsey et al. (2011a) may be due to differences in CIA immunization (chicken vs. bovine collagen) and other unknown issues with CIA model development in the present study. CIA induction for chronic dosing testing in the present study was virulent and resulted in severe swelling across all treatment groups. It is possible that the CIA in the present study was too intractable to be attenuated by chronic FAAH or MAGL inhibition. 
In addition to the behavioral assays performed in the present study, it would be informative to examine the endocannabinoid and immune cell profile of the CIA joints. RA is characterized by swelling, inflammation, pain, tenderness, and destruction of the cartilage in the synovial joints (i.e., knees, elbows, wrists, hips, and fingers) (Scott, 2010). Similar to RA patients, mice subjected to CIA have increased T-cell and pro-inflammatory cytokine response in their synovial joints and cartilage destruction (Bendele, 2001). Genetic deletion of FAAH reduces inflammation and cartilage destruction in CIA knee joints (Kinsey et al., 2011). Furthermore, the exogenous cannabinoid cannabidiol decreases TNF- $\alpha$ production in CIA synovial cells (Malfait et al., 2000). These studies indicate that MAGL inhibition might also reduce CIA-induced joint inflammation and cartilage destruction. In a subset of the present studies, we harvested knee joints for histology, and these samples await future analysis.

In conclusion, the present findings indicate that acute pharmacological inhibition of MAGL reduces thermal hyperalgesia in mice subjected to the CIA model of inflammatory arthritis. These data provide the first evidence that MAGL inhibition attenuates pain in a model of inflammatory arthritis and indicate that inhibition of MAGL is a potential targets for the development of analgesic therapeutics for chronic inflammatory pain.

\section{Acknowledgements}

We thank the thesis committee for their support and input. This project was supported financially by the National Institutes of Health [AR066806, GM104942] and by WVU startup funds. We also thank the NIDA Drug Supply Program for generously contributing the antagonists. 


\section{References}

Ahn, K., Johnson, D. S., Mileni, M., Beidler, D., Long, J. Z., McKinney, M. K., . . Cravatt, B. F. (2009). Discovery and characterization of a highly selective FAAH inhibitor that reduces inflammatory pain. Chem. Biol., 16(4), 411-420. doi: 10.1016/j.chembiol.2009.02.013

Al-Shakarchi, I., Gullick, N. J., \& Scott, D. L. (2013). Current perspectives on tocilizumab for the treatment of rheumatoid arthritis: a review. Patient Preference and Adherence, 7, 653-666. doi: http:dx.doi.org/10.2147/PPA.S41433

Asquith, D. L., Miller, A. M., McInnes, I. B., \& Liew, F. Y. (2009). Animal models of rheumatoid arthritis. Eur J Immunol, 39(8), 2040-2044. doi: 10.1002/eji.200939578.

Barton, G. M. (2008). A calculated response: control of inflammation by the innate immune system. J Clin Invest, 118(2), 413-420. doi:10.1172/JCI34431.

Bevaart, L., Vervoordeldonk, M. J., \& Tak, P. P. (2010). Evaluation of therapeutic targets in animal models of arthritis: how does it relate to rheumatoid arthritis? Arthritis Rheum., 62(8), 2192-2205. doi: 10.1002/art.27503.

Bendele, A. M. (2001). Animal models of rheumatoid arthritis. J Musculoskel Neuron Interact, 1(4), 377-385.

Billiau, A. \& Matthys, P. (2001). Modes of action of Freund's adjuvant in experimental models of autoimmune diseases. Journal of Leukocyte Biology, 70, 849-860. 
Boissier, M. C., Semerano, L., Challal, S., Saidenberg-Kermanac'h, N., \& Falgarone, G. (2012). Rheumatoid arthritis: From autoimmunity to synovitis and joint destruction. Journal of Autoimmunity, 39, 222-228. doi: 10.1016/j.jaut.2012.05.021

Brand, D. D., Latham, K. A., \& Rosloniec, E. F. (2007). Collagen-induced arthritis. Nature Protocols, 2(5), 1269-1274. doi:10.1038/nprot.2007.173

CDC. (2012, November 19). Rheumatoid arthritis. from http://www.cdc.gov/arthritis/basics/rheumatoid.htm

Chaplan, S. R., Bach, F. W., Pogrel, J. W., Chung, J. M., \& Yaksh, T. L. (1994). Quantitative assessment of tactile allodynia in the rat paw. Journal of Neuroscience Methods, 53(1), $55-63$.

Crowe, M. S., Nass, S. R., Gabella, K. M., \& Kinsey S. G. (2014). The endocannabinoid system modulates stress, emotionality, and inflammation. Brain Behav Immun, 42, 1-5. doi: 10.1016/j.bbi.2014.06.007.

Dinsen, S., Baslund, B., Lose, M., Rasmussen, A. K., Friis-Hansen, L., Hilsted, L., \& FeldtRasmussen, U. (in press). Why glucocorticoid withdrawal may sometimes be as dangerous as the treatment itself. European Journal of Internal Medicine. doi: http://dx.doi.org/10.1016/j.ejim.2013.05.014

Firestein, G. S. (2003). Evolving concepts of rheumatoid arthritis. Nature, 423, 356-361.

Gaoni, Y., \& Mechoulam, R. (1964). Isolation, structure and partial synthesis of the active constituent of hashish [Letter to the editor]. J Am Chem Soc, 86, 1646-1647. 
Ghosh, S., Wise, L. E., Yugang, C., Gujjar, R., Mahadevan, A., Cravatt, B. F., \& Lichtman, A. H. (2013). The monoacylglycerol lipase inhibitor JZL184 suppresses inflammatory pain in the mouse carrageenan model. Life Sciences, 92, 498-505. doi: 10.1016/j.lfs.2012.06.020

Guindon, J., \& Hohmann, A. G. (2009). The endocannabinoid system and pain. CNS Neurol Disord Drug Targets, 8(6), 403-421.

Herkenham, M., Lynn, A. B., Johnson, M. R., Melvin, L. S., de Costa, B. R., \& Rice, K. C. (1991). Characterization and localization of cannabinoid receptors in rat brain: a quantitative in vitro autoradiographic study. J Neurosci, 11(2), 563-583.

Ignatowska-Jankowska, B. M., Ghosh, S., Crowe, M. S., Kinsey, S. G., Niphakis, M. J., Abdullah, R. A., . . . Lichtman, A. H. (2013) In vivo characterization of the highly selective monoacylglycerol lipase inhibitor KML29: antinociceptive activity without cannabimimetic side effects. British Journal of Pharmacology, 171(6), 1392-1407. doi:10.1111/bph.12298

Inglis, J. J., Simelyte, E., McCann, F. E., Criado, G., \& Williams, R. O. (2008). Protocol for the induction of arthritis in C57BL/6 mice. Nature Protocols, 3(4), 612-618. doi: 10.1038/nprot.2008.19

Khachigian, L. M. (2006). Collagen antibody-induced arthritis. Nature Protocols, 1(5), 2512-2516. doi:10.1038/nprot.2006.393 
Kinsey, S. G., Long, J. Z., O'Neal, S. T., Abdullah, R. A., Poklis, J. L., Boger, D. L., . .

Lichtman, A. H. (2009). Blockade of endocannabinoid-degrading enzymes attenuates neuropathic pain. Journal of Pharmacology and Experimental Therapeutics, 330(3), 902910. doi: 10.1124/jpet.109.155465

Kinsey, S. G., Naidu, P. S., Cravatt, B. F., Dudley, D. T., \& Lichtman, A. H. (2011a). Fatty acid amide hydrolase blockade attenuates the development of collagen-induced arthritis and related thermal hyperalgesia in mice. Pharmacology, Biochemistry, and Behavior, 99, 718-725. doi: 10.1016/j.pbb.2011.06.022

Kinsey, S. G., Nomura, D. K., O'Neal, S. T., Long, J. Z., Cravatt, B. F., ..., \& Lichtman, A. H. (2011b). Inhibition of monoacylglycerol lipase attenuates nonsteroidal anti-inflammatory drug-induced gastric hemorrhages in mice. The Journal of Pharmacology and Experimental Therapeutics, 338(3), 795-802. doi: 10.1124/jpet.110.175778

Kinsey, S. G., O'Neal, S. T., Long, J. Z., Cravatt, B. F., \& Lichtman, A. H. (2011c). Inhibition of endocannabinoid catabolic enzymes elicits anxiolytic-like effects in the marble burying assay. Pharmacology, Biochemistry, and Behavior, 98, 21-27. doi: 10.1016/j.pbb.2010.12.002

Kinsey, S. G., Mahadevan, A., Zhao, B., Sun, H., Naidu, P. S., .., \& Lichtman, A. H. (2011d). The CB2 cannabinoid receptor-selective agonist O-3223 reduces pain and inflammation without apparent cannabinoid behavioral effects. Neuropharmacology, 60(2-3) 244-251. doi: 10.1016/j.neuropharm.2010.09.004 
Kinsey, S. G., Wise, L. E., Ramesh, D., Abdulla, R., Selley, D. E., Cravatt, b. F., \& Lichtman, A. H. (2013). Repeated Low-Dose Administration of the Monoacylglycerol Lipase Inhibitor JZL184 Retains Cannabinoid Receptor Type 1-Mediated Antinociceptive and Gastroprotective EffectsThe Journal of Pharmacology and Experimental Therapeutics, 345, 492-501. http://dx.doi.org/10.1124/jpet.112.201426

Kogan, N. M., \& Mechoulam, R. (2007). Cannabinoids in health and disease. Dialogues Clin Neurosci., 9, 413-430.

Laroche, D., Poxxo, T., Ornetti, P., Tavernier, C., \& Maillefert, J. F. (2006). Effects of loss of metatarsophalangeal joint mobility on gait in rheumatoid arhtritis patients. Rheumatology, 45, 435-440. doi:10.1093/rheumatology/kei168

Le Bars, D., Gozariu, M., \& Cadden, S. W. (2001). Animal models of nociception. Pharmacological Reviews, 53, 597-652.

Lee, Y. C. (2013). Effect and treatment of chronic pain in inflammatory arthritis. Curr Rheumatol Rep, 300(15), 1-8. doi: 10.1007/s11926-012-0300-4

Li, P. \& Schwarz, E. M. (2003). The TNF- $\alpha$ transgenic mouse model of inflammatory arthritis. Springer Semin Immunopathol, 25, 19-33. DOI 10.1007/s00281-003-0125-3

Lichtman, A. H., Shelton, C. C., Advania, T., \& Cravatt, B. F. (2004). Mice lacking fatty acid amide hydrolase exhibit a cannabinoid receptor-mediated phenotypic hypoalgesia Pain, 109, 319-327. doi:10.1016/j.pain.2004.01.022 
Long, J. Z., Li, W., Booker, L., Burston, J. J., Kinsey, S. G., Schlosburg, J. E., . . Cravatt, B. F. (2009). Selective blockade of 2-arachidonoylglycerol hydrolysis produces cannabinoid behavioral effects. Nature Chemical Biology, 5(1), 37-44. doi: 10.1038/nchembio.129

Luchicchi, A., \& Pistis, M. (2013). Anandamide and 2-arachidonoylglycerol: Pharmacological properties, functional features, and emerging specificities of the two major endocannabinoids. Mol Neurobiol, 46, 374-392. doi: 10.1007/s12035-012-8299-0

Malfait, A. M., Gallily, R., Sumariwalla, P. F., Malik, A. S., Andreakos, E., Mechoulam, R., \& Feldmann. (2000). The nonpsychoactive cannabis constituent cannabidiol is an oral antiarthritic therapeutic in murine collagen-induced arthritis. Proc. Natl. Acad. Sci., 97(17), 9561-9566. doi: 10.1073ypnas.160105897

Mechoulam, R., \& Parker, L. A. (2013). The endocannabinoid system and the brain. Annual Review of Psychology, 64, 6.1-6.27. doi: 10.1146/annurev-psych-113011-143739

Medzhitov, R. (2008). Origin and physiological roles of inflammation. Nature, 454, 428-435. doi: 10.1038/nature07201

Moreland, L. W., \& Curtis, J. R. (2008). Systemic nonarticular manifestations of rheumatoid arthritis: focus on inflammatory mechanisms. Seminars in Arthritis and Rheumatism, 39, 132-143. doi: 10.1016/j.semarthrit.2008.08.003

Naidu, P. S., Kinsey, S. G., Guo, T. L., Cravatt, B. F., \& Lichtman, A. H. (2010). Regulation of inflammatory pain by inhibition of fatty acid amide hydrolase. The Journal of 
Pharmacology and Experimental Therapeutics, 334(1), 182-190. doi:

doi:10.1124/jpet.109.164806

Nass, S. R., Long, J. Z., Schlosburg, J. E., Cravatt, B. F., Lichtman, A. H., \& Kinsey S. G. (2015). Endocannabinoid catabolic enzymes play differential roles in thermal homeostasis in response to environmental or immune challenge. J Neuroimmune Pharmacol. Advanced online publication.

Ozdemir H., Guvenal T., Cetin M., Kaya T., \& Cetin A. (2003). A Placebo-Controlled Comparison of Effects of Repetitive Doses of Betamethasone and Dexamethasone on Lung Maturation and Lung, Liver, and Body Weights of Mouse Pups. Pediatric Research. 53(1), 98-103. doi: 10.1203/01.PDR.0000039765.55591.31

Rom, S., \& Persidsky, Y. (2013). Cannabinoid receptor 2: Potential role in immunomodulation and neuroinflammation. J Neuroimmune Pharmacol, 8, 608-620. doi: 10.1007/s11481013-9445-9

Schlosburg, J. E., Kinsey, S. G., \& Lichtman, A. H. (2009). Targeting fatty acid amide hydrolase (FAAH) to treat pain and inflammation. The AAPS Journal, 11(1), 39-44. doi: $10.1208 / \mathrm{s} 12248-008-9075-\mathrm{y}$

Schlosburg, J. E., Blankman, J. L., Long, J. Z., Nomura, D. K., Pan, B., Kinsey, S. G., Nguyen, P. T., . . Cravatt, B. F. (2010). Chronic monoacylglycerol lipase blockade causes functional antagonism of the endocannabinoid system. Nat Neurosci.,13(9), 1113-1119. doi:10.1038/nn.2616. 
Scholz, J., \& Woolf, C. J. (2002). Can we conquer pain? Nature Neuroscience Supplement, 5, 1062-1067. doi: 10.1038/nn942

Scrivo, R., Franco, M. D., Spadaro, A., \& Valesini, G. (2007). The immunology of rheumatoid arthritis. Annals of the New York Academy of Sciences, 1108, 312-322. doi: 10.1196/annals. 1422.033

Sumariwalla, P. F., Gallily, R., Tchilibon, S., Fride, E., Mechoulam, R., \& Feldmann, M. (2004). A novel synthetic, nonpsychoactive cannabinoid acid (HU-320) with antiinflammatory properties in murine collagen-induced arthritis. Arthritis \& Rheumatism, 50(3), 985-998. doi: 10.1002/art.20050

Thomas A, Burant A, Bui N, Graham D, Yuva-Paylor LA, Paylor R. (2009). Marble burying reflects a repetitive and perseverative behavior more than novelty-induced anxiety. Psychopharmacology (Berl.), 204(2), 361-73. doi: 10.1007/s00213-009-1466-y.

Wallace, J. L. (2008). Prostaglandins, NSAIDS, and gastric mucosal protection: Why doesn't the stomach digest itself? Physiol Rev, 88, 1547-1565. doi: 10.1152/physrev.00004.2008

Walsh, D. A., \& McWilliams, D. F. (2012). Pain in Rheumatoid Arthritis. Curr Pain Headache Rep, 16, 509-517. doi: 10.1007/s11916-012-0303-x 


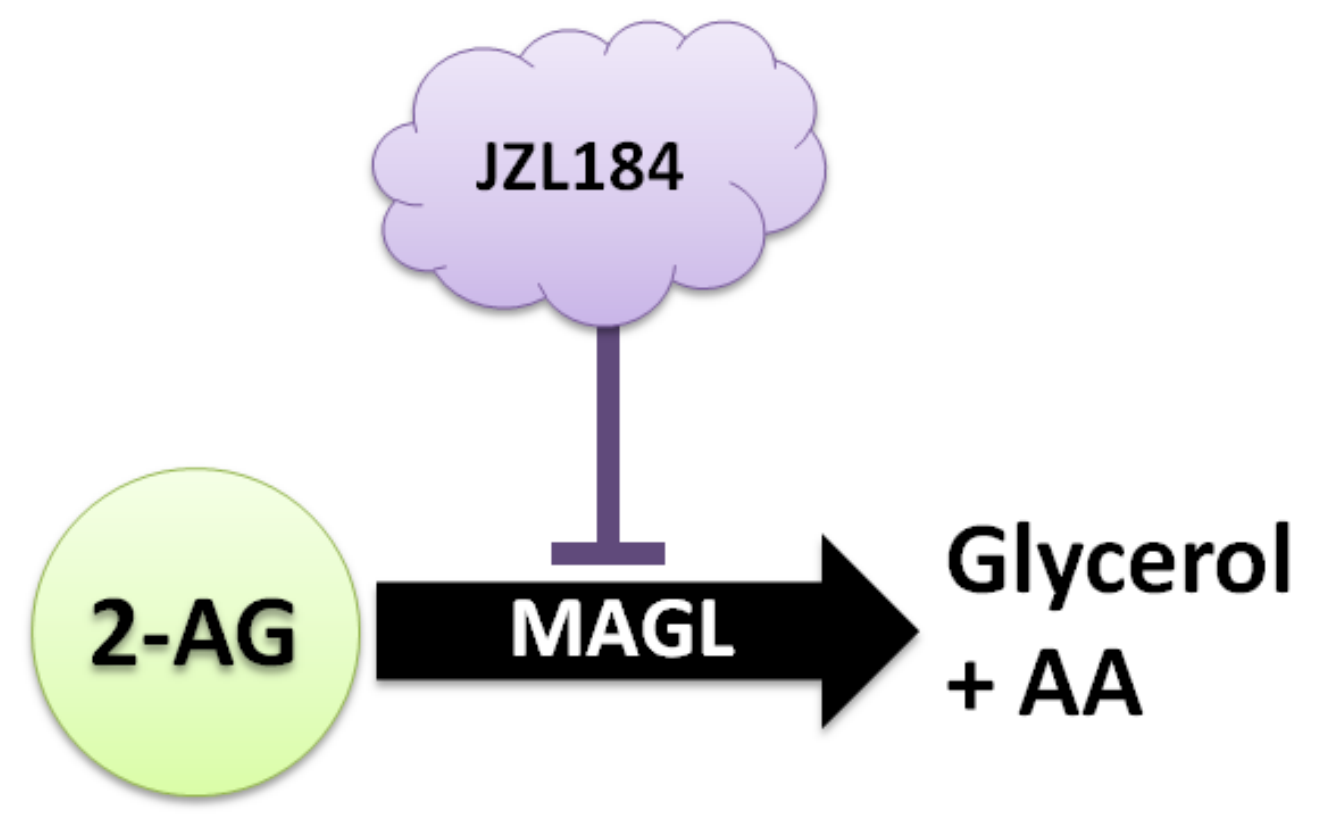

Figure 1. Schematic drawing of endocannabinoid metabolism. The endocannabinoid 2arachidonoylglycerol (2-AG) is metabolized by the enzyme monoacylglycerol lipase (MAGL) into glycerol and arachidonic acid (AA). Pharmacological inhibition of MAGL with the compound JZL184 indirectly increases brain levels of 2-AG by blocking its metabolism. 
A
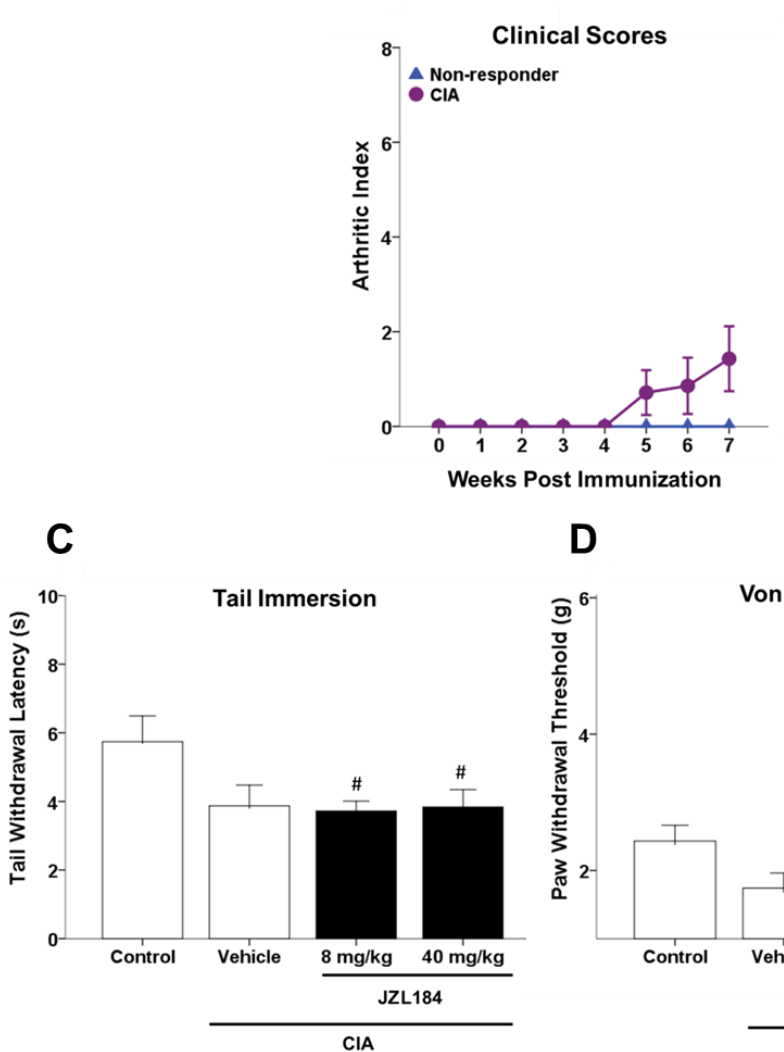

B

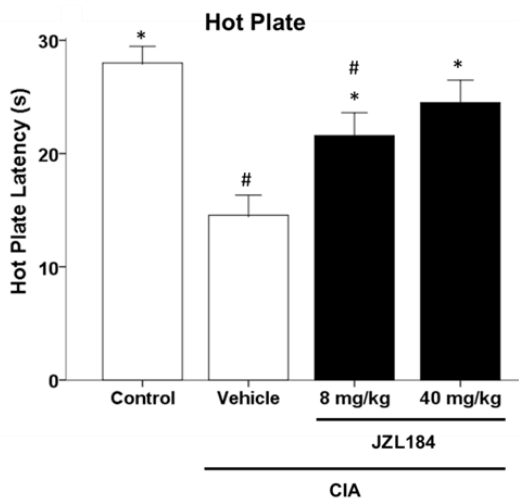

D

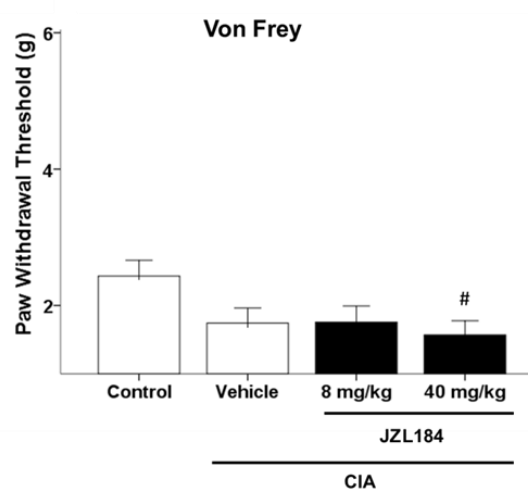

E

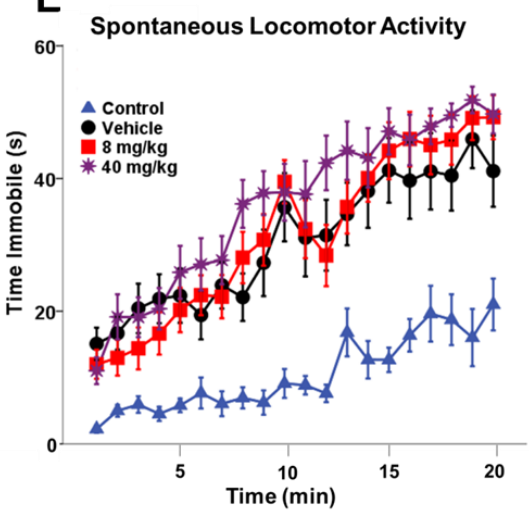

Figure 3. The MAGL inhibitor JZL184 ( 8 \& $40 \mathrm{mg} / \mathrm{kg}$ ) reduced hyperalgesia in mice subjected to collagen-induced arthritis (CIA). Mice were subjected to CIA, and $18 \%$ of CIA mice developed arthritic symptoms. Clinical scores for mice were measured (A). Mice were injected i.p. with JZL184 (8 \& $40 \mathrm{mg} / \mathrm{kg}$ ). Mice were tested for thermal hyperalgesia on the hot plate (B) and tail immersion $(\mathbf{C})$ tests. Mechanical allodynia was tested via the von Frey test (D). Locomotor suppression was tested via spontaneous locomotor activity test (E). Data expressed as mean $\pm \operatorname{SEM}(\mathrm{n}=14-16) . * \mathrm{p}<0.05$ vs. vehicle CIA mice; $\# \mathrm{p}<0.05$ vs. vehicle control mice. 
A

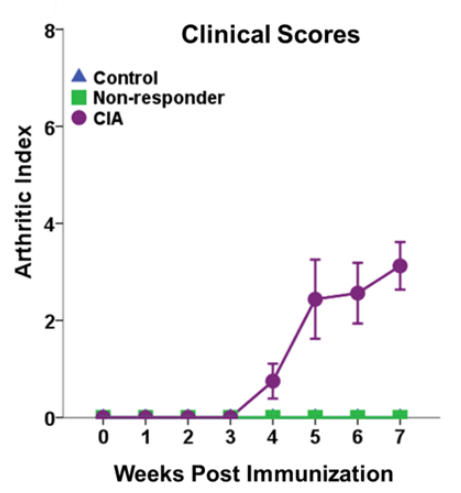

D

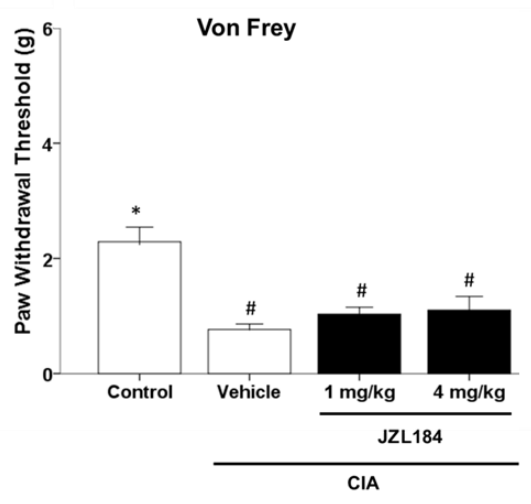

B

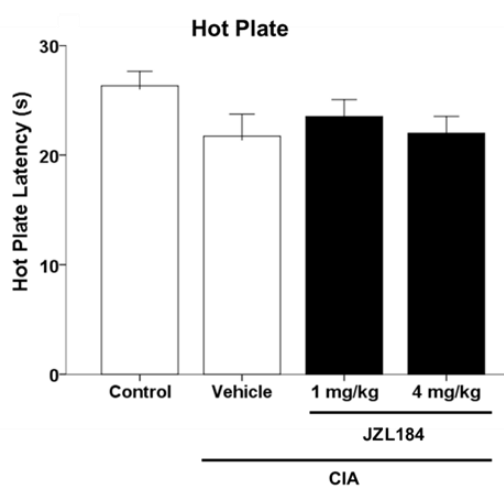

E

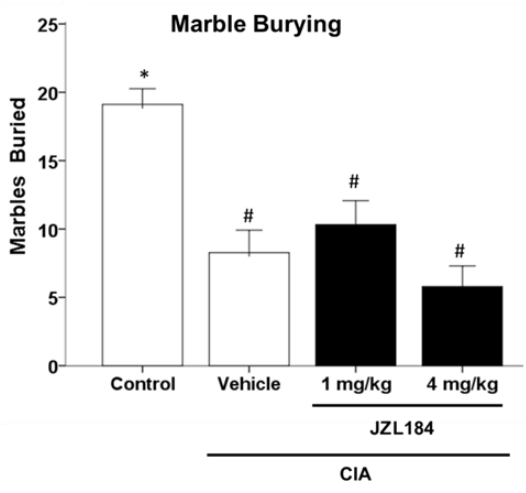

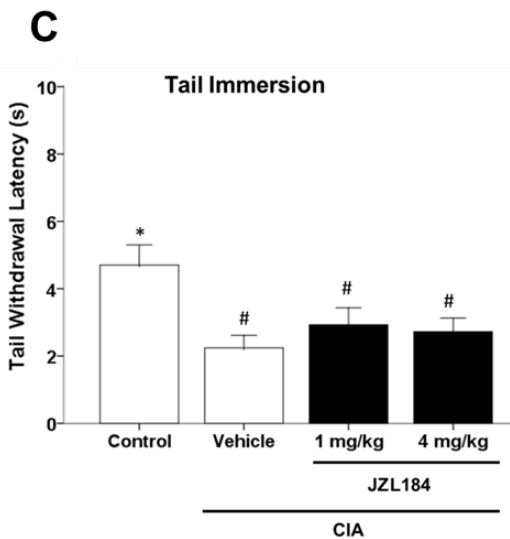

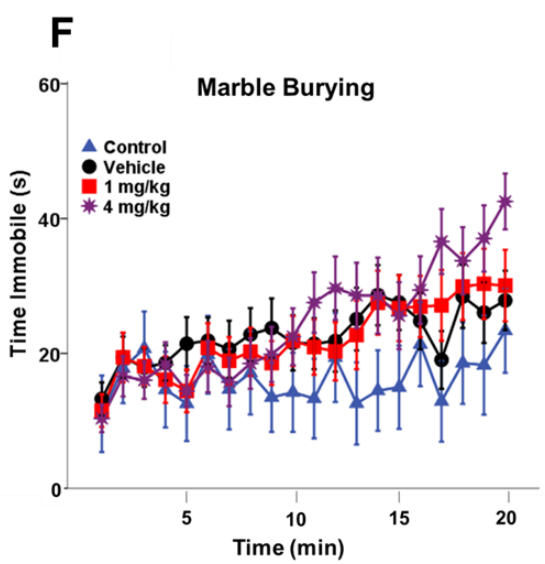

Figure 4. The MAGL inhibitor JZL184 (1 \& $4 \mathrm{mg} / \mathrm{kg})$ did not affect hyperalgesia, allodynia, or locomotor activity in mice subjected to collagen-induced arthritis (CIA). Mice were subjected to CIA, and $38 \%$ of CIA mice developed arthritic symptoms. Clinical scores for mice were measured (A). Mice were injected i.p. with JZL184 (1 \& 4 mg/kg). Mice were tested for thermal hyperalgesia on the hot plate $(\mathbf{B})$ and tail immersion $(\mathbf{C})$ tests. Mechanical allodynia was tested via the von Frey test $(\mathbf{D})$. Marbles buried $(\mathbf{E})$ and locomotor suppression $(\mathbf{F})$ was tested via the marble burying test. Data expressed as mean \pm SEM $(n=9-21) . * p<0.05$ vs. vehicle CIA mice; \# $\mathrm{p}<0.05$ vs. vehicle control mice. 
A

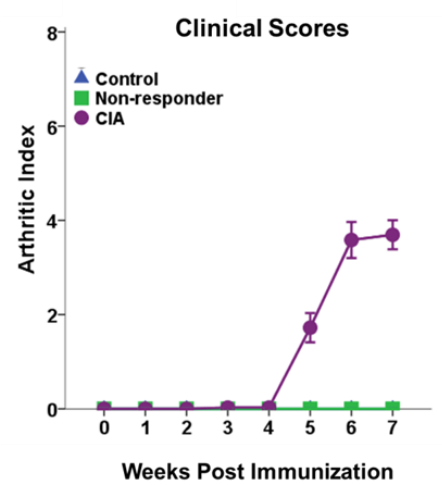

D

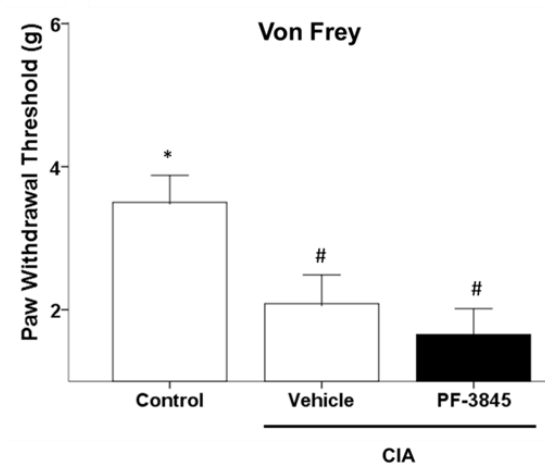

B

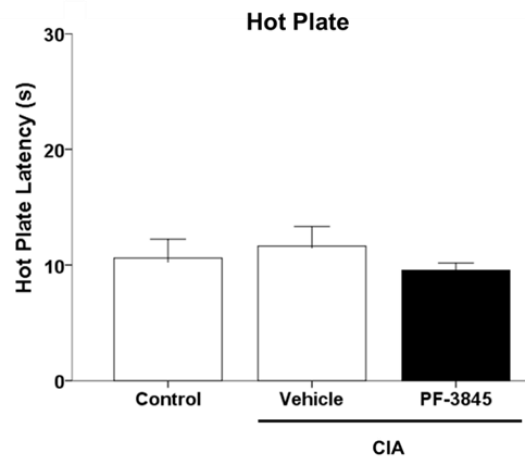

$\mathbf{E}$

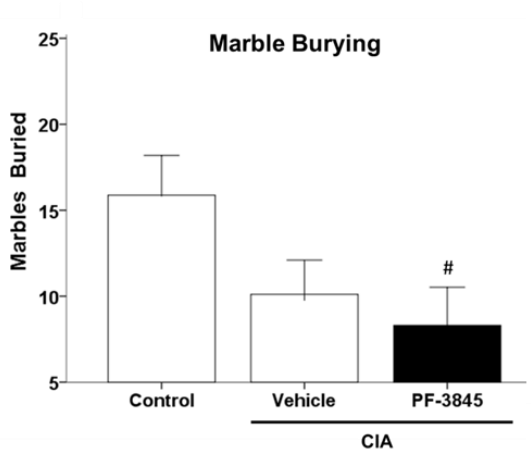

C
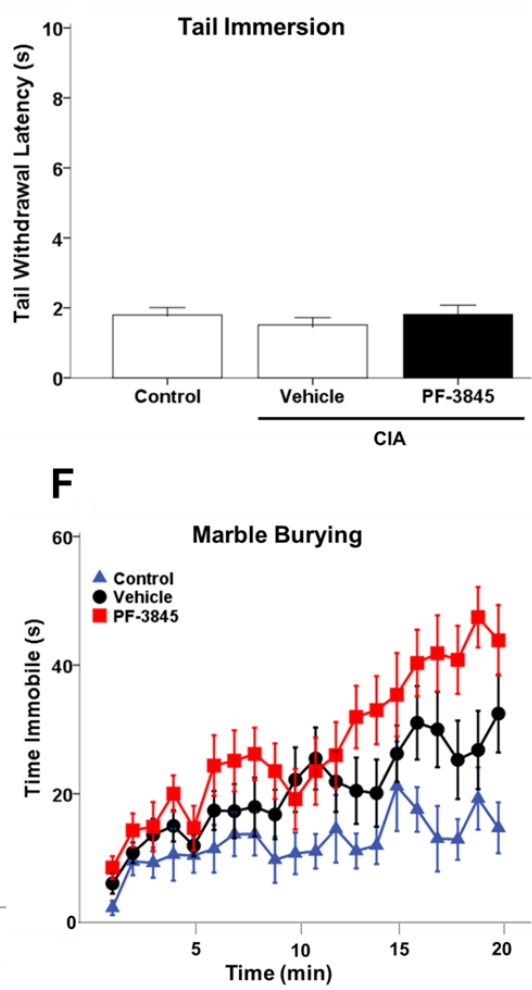

Figure 5. The FAAH inhibitor PF-3845 did not affect hyperalgesia, allodynia, or locomotor activity in mice subjected to collagen-induced arthritis (CIA). Mice were subjected to CIA, and 90\% of CIA mice developed arthritic symptoms. Clinical scores for mice were measured (A). Mice were injected i.p. with PF-3845 (10 mg/kg). Mice were tested for thermal hyperalgesia on the hot plate $(\mathbf{B})$ and tail immersion $(\mathbf{C})$ tests. Mechanical allodynia was tested via the von Frey test (D). Marbles buried (E) and locomotor suppression $(\mathbf{F})$ was tested via the marble burying test. Data expressed as mean $\pm \operatorname{SEM}(\mathrm{n}=8-12)$. $* \mathrm{p}<0.05$ vs. vehicle CIA mice; $\# \mathrm{p}<0.05$ vs. vehicle control mice. 

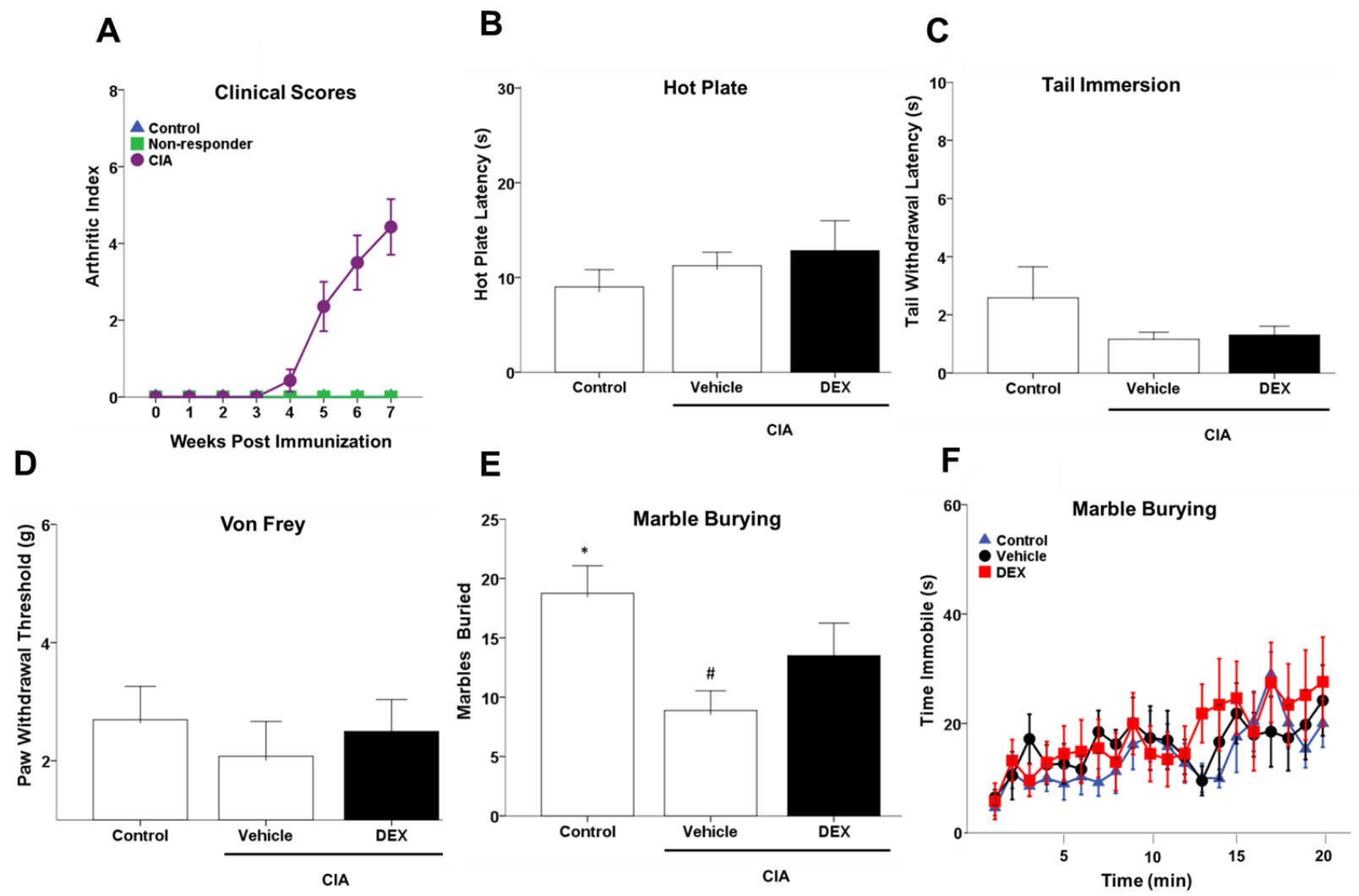

Figure 6. The glucocorticoid dexamethasone (DEX) did not affect hyperalgesia, allodynia, or locomotor activity in mice subjected to collagen-induced arthritis (CIA). Mice were subjected to CIA, and $77 \%$ of CIA mice developed arthritic symptoms. Clinical scores for mice were measured (A). Mice were injected i.p. with DEX (2 mg/kg). Mice were tested for thermal hyperalgesia on the hot plate $(\mathbf{B})$ and tail immersion $(\mathbf{C})$ tests. Mechanical allodynia was tested via the von Frey test (D). Marbles buried (E) and locomotor suppression $(\mathbf{F})$ was tested via the marble burying test. Data expressed as mean $\pm \operatorname{SEM}(n=8) . * p<0.05$ vs. vehicle CIA mice; \# $\mathrm{p}<0.05$ vs. vehicle control mice. 


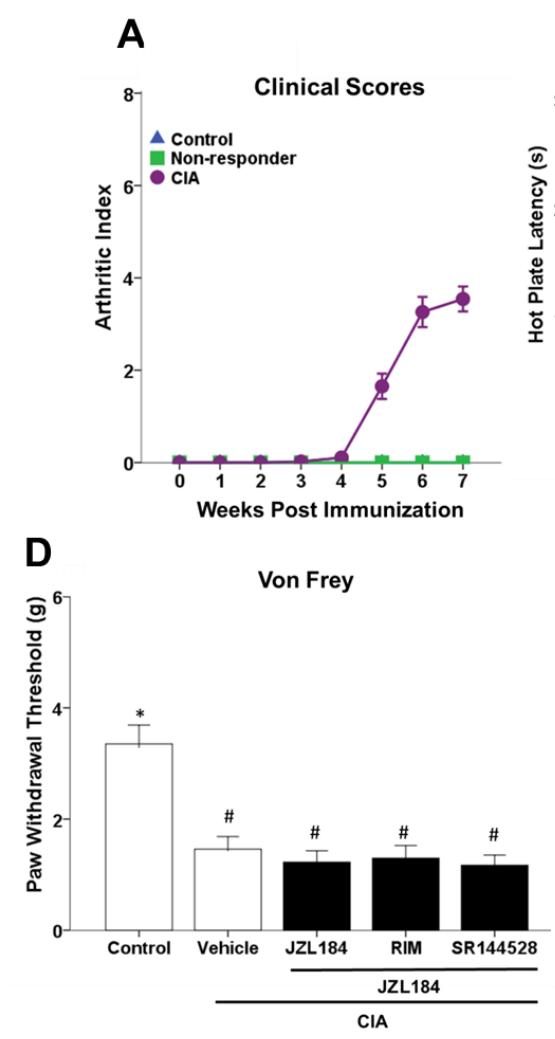

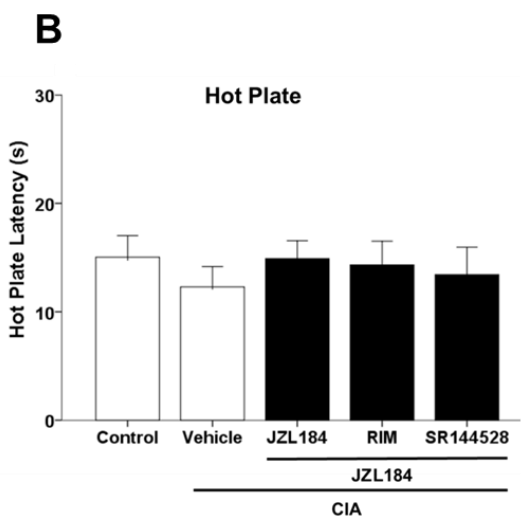

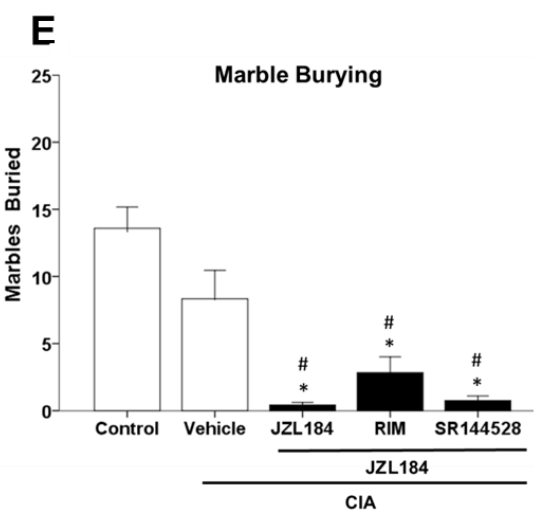

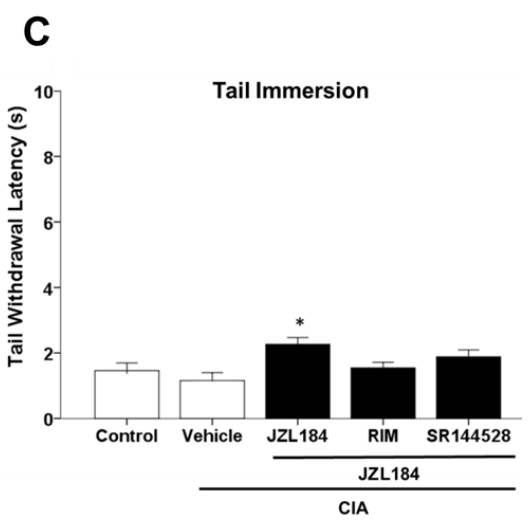

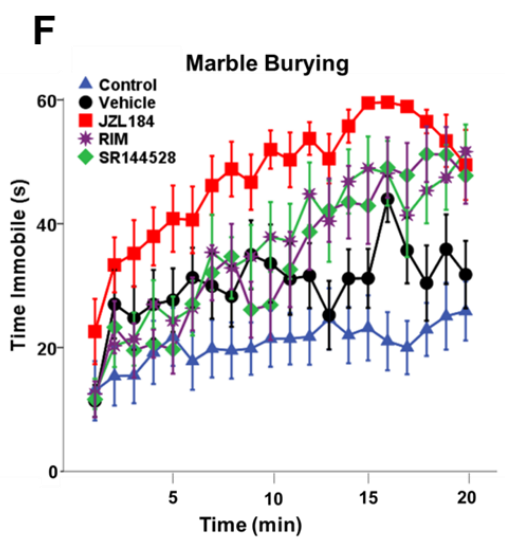

Figure 7. The MAGL inhibitor JZL184 did not affect hyperalgesia, allodynia, or locomotor activity in mice subjected to collagen-induced arthritis (CIA). Therefore, rimonabant (3 mg/kg) and SR144528 (3 mg/kg) did not block JZL184 effects. Mice were subjected to CIA, and 66\% of CIA mice developed arthritic symptoms. Clinical scores for mice were measured (A). Mice were injected i.p. with JZL184 (40 mg/kg). Mice were tested for thermal hyperalgesia on the hot plate (B) and tail immersion (C) tests. Mechanical allodynia was tested via von Frey test (D). Marbles buried (E) and locomotor suppression (F) was tested via the marble burying test. Data expressed as mean $\pm \operatorname{SEM}(n=12) . * p<0.05$ vs. vehicle CIA mice; $\# \mathrm{p}<0.05$ vs. vehicle control mice. 


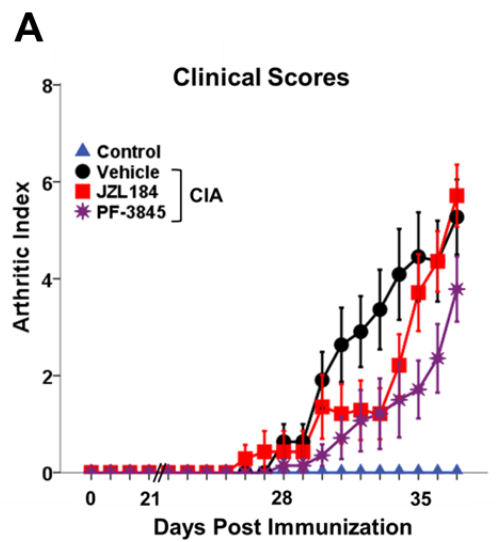

C

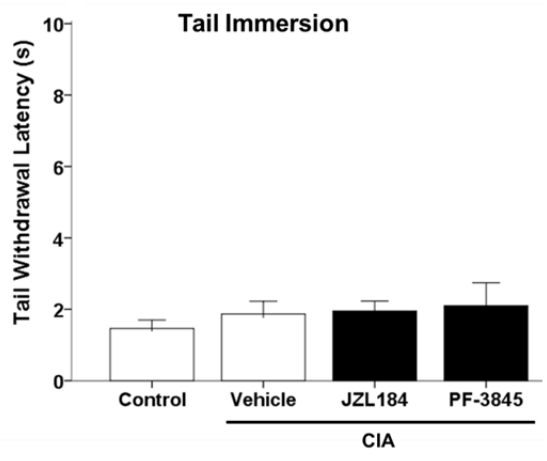

D

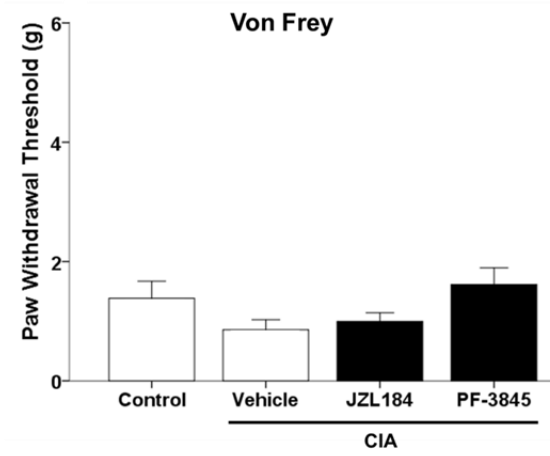

B

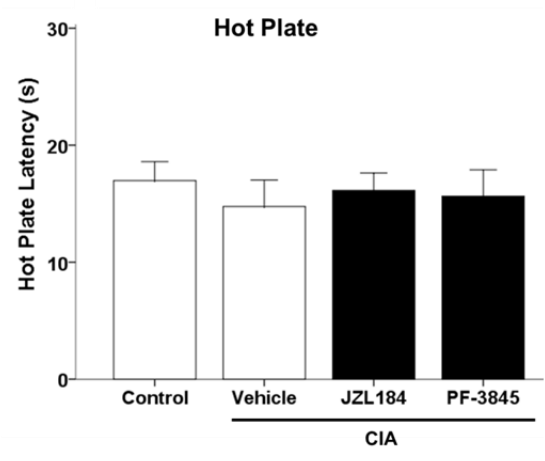

E

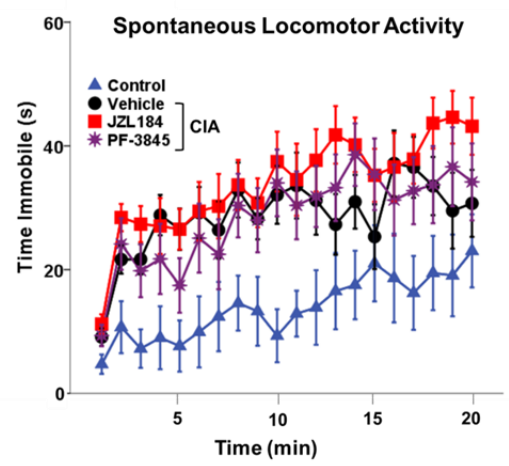

Figure 8. Chronic dosing of the MAGL inhibitor JZL184 and the FAAH inhibitor PF-3845 did not affect hyperalgesia, allodynia, or locomotor activity in mice subjected to collagen-induced arthritis (CIA). Mice were subjected to CIA, and 98\% of CIA mice developed arthritic symptoms. Clinical scores for mice were measured (A). Mice were injected s.c. with JZL184 (8 $\mathrm{mg} / \mathrm{kg})$ or PF-3845 (10 mg/kg) for 15 days. Mice were tested for thermal hyperalgesia on the hot plate (B) and tail immersion (C) tests. Mechanical allodynia was tested via the von Frey test (D). Locomotor suppression was tested via spontaneous locomotor activity test (E). Data expressed as mean $\pm \operatorname{SEM}(\mathrm{n}=8-14) .{ }^{*} \mathrm{p}<0.05$ vs. vehicle CIA mice; $\# \mathrm{p}<0.05$ vs. vehicle control mice. 


\section{Appendix A.}

A

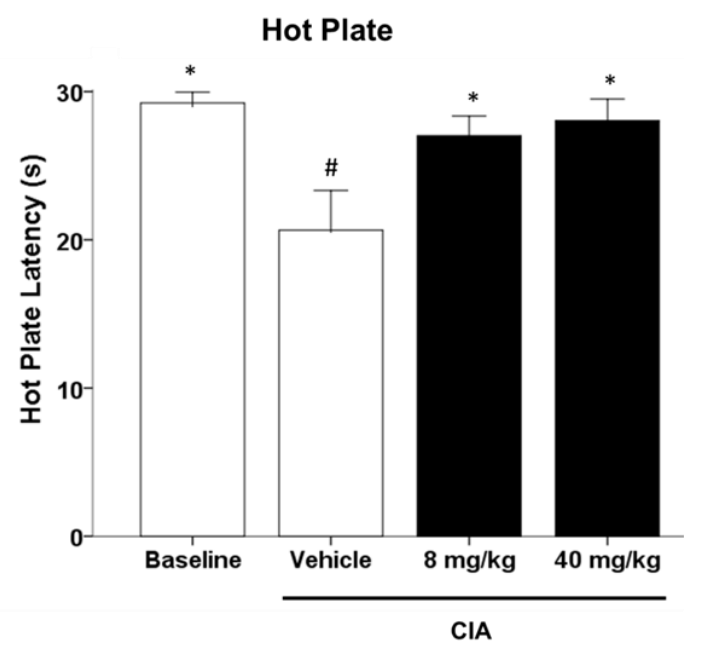

B

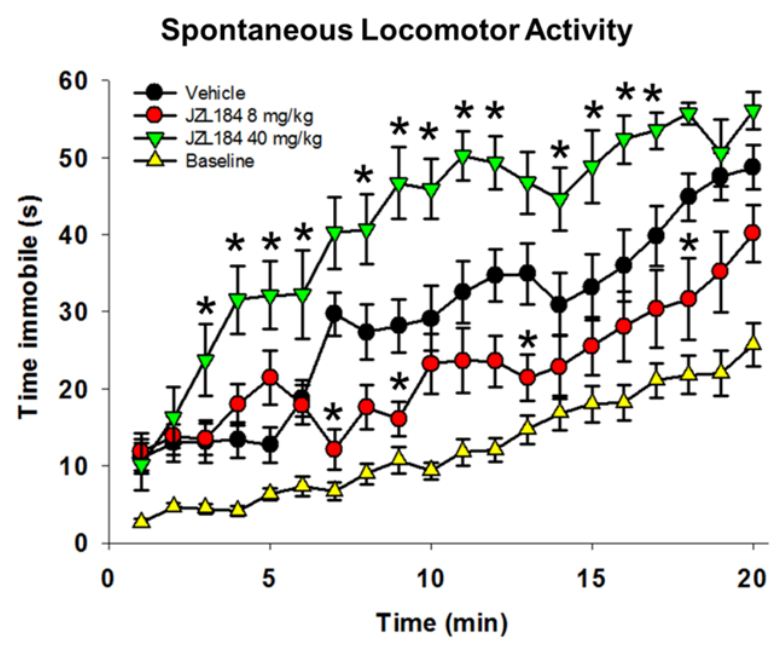

Figure A1. The MAGL inhibitor JZL184 reduced hyperalgesia and suppressed locomotor activity in mice subjected to collagen-induced arthritis (CIA). Mice were subjected to CIA, and $55 \%$ of CIA mice developed arthritic symptoms. Approximately $100 \mu \mathrm{l}$ of an emulsion consisting of type II chicken collagen, dissolved in $0.1 \mathrm{M}$ acetic acid, in an equal volume of complete Freund's adjuvant (CFA) was injected subcutaneously near the base of the tail. 14 days later, mice were given a "booster" exposure to collagen in an equal volume of incomplete Freund's adjuvant (IFA), as detailed above. 1 month later, mice were given a secondary "booster" exposure to type II bovine collagen in an equal volume of CFA into the tail. Mice were injected i.p. with JZL184 ( $8 \& 40 \mathrm{mg} / \mathrm{kg}$ ). Mice were tested for thermal hyperalgesia on the hot plate (A) test. Locomotor suppression was tested via spontaneous locomotor activity test (B). Data expressed as mean $\pm \operatorname{SEM}(\mathrm{n}=12-13) .{ }^{*} \mathrm{p}<0.05$ vs. vehicle CIA mice; $\# \mathrm{p}<0.05$ vs. vehicle baseline mice. 


\section{Appendix B.}

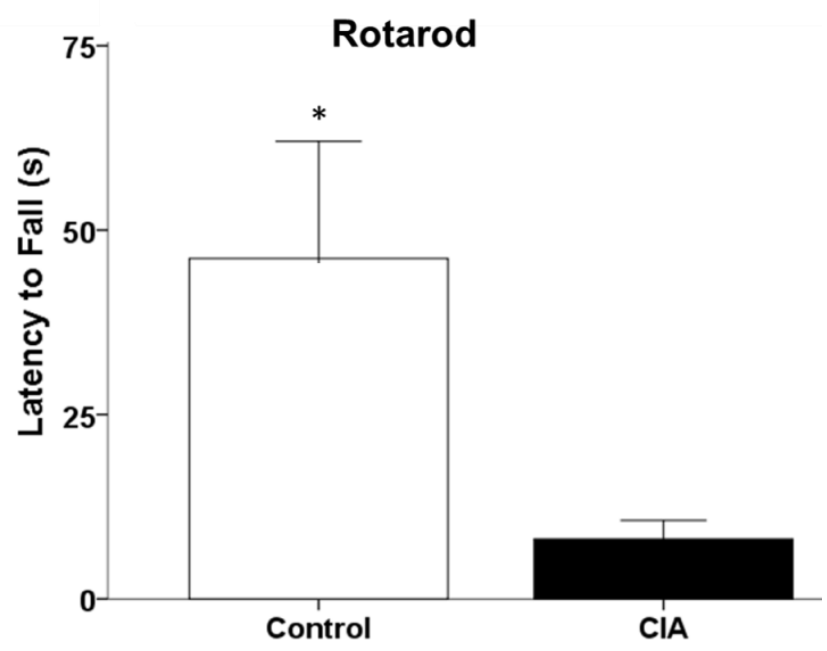

Figure B1. Collagen-induced arthritis (CIA) reduced motor coordination. The rotarod test was used to measure motor coordination. Mice were placed in individual lanes on a rod rotating at 4 RPM. Latency to fall off the rod was measured as the dependent variable. Data expressed as mean $\pm \operatorname{SEM}(\mathrm{n}=8-15) . * \mathrm{p}<0.05$ vs. vehicle control mice. 